Movie DR1

Movie DR2

\title{
-Supplementary material- Oblique Rifting in the Equatorial Atlantic: Why there is no Saharan Atlantic Ocean
}

\author{
Christian Heine ${ }^{1 *}$ Sascha Brune $e^{1,2 \dagger}$ \\ ${ }^{1}$ EarthByte Research Group, School of Geosciences, \\ The University of Sydney, NSW 2006, Australia \\ ${ }^{2}$ GFZ-Potsdam, Geodynamic Modelling Section, 14473 Potsdam, Germany
}

$2013-12-13$

\section{Contents}

$1 \quad$ Numerical model description 1

1.1 Model setup . . . . . . . . . . . . . . . . . . . . . . . 1

1.2 Thermal setup . . . . . . . . . . . . . . . . . . 2

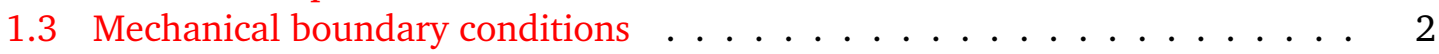

1.4 Weakening mechanisms ..................... 4

2 Alternative numerical model setups $\quad 4$

3 Plate tectonic reconstructions $\quad 6$

\section{Numerical model description}

\subsection{Model setup}

We apply the finite element code SLIM3D (Semi-Lagrangian Implicit Model for 3 dimensions; Popov and Sobolev, 2008) to solve the coupled system of conservation equations for momentum, thermal energy and constitutive equations that include the effects temperaturand stress-dependent viscosity and elastic compressibility. Our simulation domain measures $2400 \mathrm{~km}$ times $1600 \mathrm{~km}$ horizontally and $200 \mathrm{~km}$ vertically. We thereby use 192000

*mailto:chhei@mensa.uberspace.de

†mailto:brune@gfz-potsdam.de 
cubic elements with a horizontal and vertical dimension of $20 \mathrm{~km}$ and $10 \mathrm{~km}$, respectively. The implicit time stepping of the code allows for a step size of $20 \mathrm{ky}$. The lithospheric segment is vertically divided in four distinct petrological layers: $20 \mathrm{~km}$ of felsic upper crust, $20 \mathrm{~km}$ of mafic lower crust, $80 \mathrm{~km}$ of strong lithospheric mantle, and $80 \mathrm{~km}$ of weak asthenospheric mantle. Rheological parameters of the crust (Supplementary Table 1) are chosen to represent a narrow rift setting as it is evident in the Equatorial Atlantic by the short amount of thinned continental crust. The rheology of lithospheric and asthenospheric mantle is based on laboratory creep measurements for dry and wet olivine, respectively.

\subsection{Thermal setup}

The pattern of Gondwanaland break-up shows that lithospheric extension occurred within mobile belts (Ziegler and Cloetingh, 2004). It is still unknown which mechanism is responsible for the mechanical memory of these intracontinental suture zones: inherited faults, crustal lithology, foliations in crustal rocks or anisotropy of olivine crystals in the mantle (Tommasi and Vauchez, 2001). However, each of these mechanism leads to local strength reduction and if the suture zone is thrown into extension, all of these processes lead to lithospheric necking and hot asthenospheric upwelling. In our model, we introduce inheritance via a thermal temperature perturbation at the bottom of the mobile belt lithosphere: We position the thermal lithosphere-asthenosphere boundary depth $\left(1350{ }^{\circ} \mathrm{C}\right)$ to $120 \mathrm{~km}$ in mobile belts and to $150 \mathrm{~km}$ depth in the surrounding plate interiors. Both values are derived from recent compilations of lithosphere thickness in Africa (Artemieva, 2006). The initial temperature distribution of the model results from a thermal equilibrium that is defined by material parameters (radiogenic heat production and conductivity, see Supplementary Table 1) and the following boundary conditions: The surface temperature is held constant at $0{ }^{\circ} \mathrm{C}$, whereas below the initial lithosphere-asthenosphere depth, the asthenosphere temperature is set to $1350{ }^{\circ} \mathrm{C}$. Lateral boundaries are thermally isolated. During subsequent model evolution we fix the bottom boundary temperature to $1350{ }^{\circ} \mathrm{C}$ allowing for a self-consistent evolution of lithosphere thickness.

\subsection{Mechanical boundary conditions}

We apply dynamic boundary conditions at the model sides normal to x-direction: During the rift process, the boundary force is kept constant which allows for self-consistent evolution of extensional velocities. This approach is feasible if the model domain comprises a large region whose strength is a major component in the overall force balance of the involved plates. In our case, we assume that the westward motion of the South American plate results from the balance of proto-Andean subduction forces, mantle drag and the resisting strength of the involved rift segments (SARS, EqRS, WARS, CARS). The northern and south-eastern boundaries of the South Atlantic plate consist of low-strength mid ocean ridges. The constant boundary force is maintained in our model until extensional velocities 


\begin{tabular}{|c|c|c|c|c|}
\hline Parameter & $\begin{array}{l}\text { Upper } \\
\text { Crust }\end{array}$ & $\begin{array}{l}\text { Lower } \\
\text { Crust }\end{array}$ & $\begin{array}{l}\text { Strong } \\
\text { Mantle }\end{array}$ & $\begin{array}{l}\text { Weak } \\
\text { Mantle }\end{array}$ \\
\hline Density, $\rho\left(\mathrm{kg} \mathrm{m}^{-3}\right)$ & 2700 & 2850 & 3300 & 3300 \\
\hline Thermal expansivity, $\alpha\left(10^{-5} \mathrm{~K}^{-1}\right)$ & 2.7 & 2.7 & 3.0 & 3.0 \\
\hline Bulk modulus, $K$ (GPa) & 55 & 63 & 122 & 122 \\
\hline Shear modulus, $G$ (GPa) & 36 & 40 & 74 & 74 \\
\hline Heat capacity, $C_{p}\left(\mathrm{~J} \mathrm{~kg}^{-1} \mathrm{~K}^{-1}\right)$ & 1200 & 1200 & 1200 & 1200 \\
\hline Heat conductivity, $\lambda$ (W K ${ }^{-1} \mathrm{~m}^{-1}$ ) & 2.5 & 2.5 & 3.3 & 3.3 \\
\hline Radiogenic heat production, $A\left(\mu \mathrm{W} \mathrm{m}^{-3}\right)$ & 1.5 & 0.2 & 0 & 0 \\
\hline Initial friction coefficient, $\mu(-)$ & 0.6 & 0.6 & 0.6 & 0.6 \\
\hline Maximum plastic friction softening* & $90 \%$ & $90 \%$ & none & none \\
\hline Cohesion, $c$ (MPa) & 5.0 & 5.0 & 5.0 & 5.0 \\
\hline $\begin{array}{l}\text { Pre-exponential constant for diffusion } \\
\text { creep, } \log \left(B_{D i f f}\right)\left(\mathrm{Pa}^{-1} \mathrm{~s}^{-1}\right) \\
\text { Activation energy for diffusion creep, }\end{array}$ & - & - & -8.65 & -8.65 \\
\hline $\begin{array}{l}E_{\text {Diff }}\left(\mathrm{kJ} \mathrm{mol}^{-1}\right) \\
\text { Activation volume for diffusion creep, }\end{array}$ & - & - & 375 & 335 \\
\hline$V_{D i f f}\left(10^{-6} \mathrm{~m}^{-3} / \mathrm{mol}\right)$ & - & - & 6 & 4 \\
\hline $\begin{array}{l}\text { Pre-exponential constant for dislocation } \\
\text { creep, } \log \left(B_{\text {Disloc }}\right)\left(\mathrm{Pa}^{-\mathrm{n}} \mathrm{s}^{-1}\right) \\
\text { Power law exponent for dislocation }\end{array}$ & -28.0 & -21.05 & -15.56 & -15.05 \\
\hline $\begin{array}{l}\text { creep, } n \\
\text { Activation energy for dislocation creep, }\end{array}$ & 4.0 & 4.2 & 3.5 & 3.5 \\
\hline $\begin{array}{l}E_{\text {Disloc }}\left(\mathrm{kJ} \mathrm{mol}^{-1}\right) \\
\text { Activation volume for dislocation creep, }\end{array}$ & 223 & 445 & 530 & 480 \\
\hline$V_{\text {Disloc }}\left(10^{-6} \mathrm{~m}^{-3} / \mathrm{mol}\right)$ & 0 & 0 & 13 & 10 \\
\hline
\end{tabular}

Table DR1: Numerical model parameters. Dislocation creep parameters for upper crust: wet quartzite (Gleason and Tullis, 1995), lower crust: mafic granulite (Wilks and Carter, 1990), strong mantle: dry olivine (Hirth and Kohlstedt, 2003), weak mantle: wet olivine, i.e. $500 \mathrm{ppm} \mathrm{H/Si} \mathrm{(Hirth} \mathrm{and} \mathrm{Kohlstedt,} \mathrm{2003).} \mathrm{Olivine} \mathrm{grain} \mathrm{size} \mathrm{is} \mathrm{held} \mathrm{constant} \mathrm{at} 6 \mathrm{~mm}$ and is included in the pre-exponential factors. *linear decrease of $\mu$ from 0.6 to 0.06 between 0 and 1 strain. 
reach typical sea-floor spreading amplitudes. Once this happens, rift strength is so low that it does not contribute to the force balance of the South American plate anymore. Hence, the South American plate velocity results from subduction forces and mantle drag only. This stage is represented in our model by using velocity boundary conditions at the model side facing in $\mathrm{x}$-direction.

For the upper and lower model boundaries we use a free surface and isostatic Winkler support, respectively. During remeshing, the lower boundary is reset to $200 \mathrm{~km}$, whereby Lagrangian markers are either deleted or introduced. Throughout the simulation, boundary conditions in y-direction involve a continuous stress formulation, i.e. the face-parallel components of the stress tensor inside and outside the model domain are forced to be identical while non-zero face-perpendicular velocities are not allowed. This formulation is an extension of the free-slip boundary condition as the latter has the disadvantage that model boundaries are not able to sustain shear stresses and therefore represent enormous vertical faults cutting through the whole lithosphere.

\subsection{Weakening mechanisms}

Narrow shear zones localize in the model domain generated by three thermo-mechanical weakening feedbacks: (1) Frictional strain softening is implemented via a strain-dependent effective friction coefficient that decreases linearly from 0.6 to 0.06 if the plastic strains increases from 0 and 1 while it remains constant at 0.06 for plastic strains larger than 1 . (2) A temperature increase due to viscous and plastic deformation (i.e. shear heating) reduces the viscosity. (3) Nonlinear stress dependence in the dislocation creep law results in strain rate softening and localized viscosity decrease.

However, the strongest weakening effect in our rift models derives from lithospheric thinning and upwelling of hot asthenospheric material (Brune et al., 2012). Since extensional deformation and subsequent necking are attracted to regions of low lithospheric strength, weak lithospheric areas will undergo a pronounced localization feedback.

\section{Alternative numerical model setups}

In order to test the robustness of our model results, a number of experiments have been conducted where we varied the general rift geometry, the model side where extension is applied, lithosphere and crustal thickness, rheology and initial rift width. All setups lead to the same outcome that the oblique rift is mechanically favored. Here, we depict the simulations where extension is applied to the opposite model side (Supplementary Figure 1-a), where the initial rift configuration is simplified (Supplementary Figure 1-b) and where the competing rift branches do not intersect (Supplementary Figure 1-c).

Applying extension at the opposite model edge (Supplementary Figure 1-a) essentially represents a different motion of the model domain with respect to the asthenosphere. This 

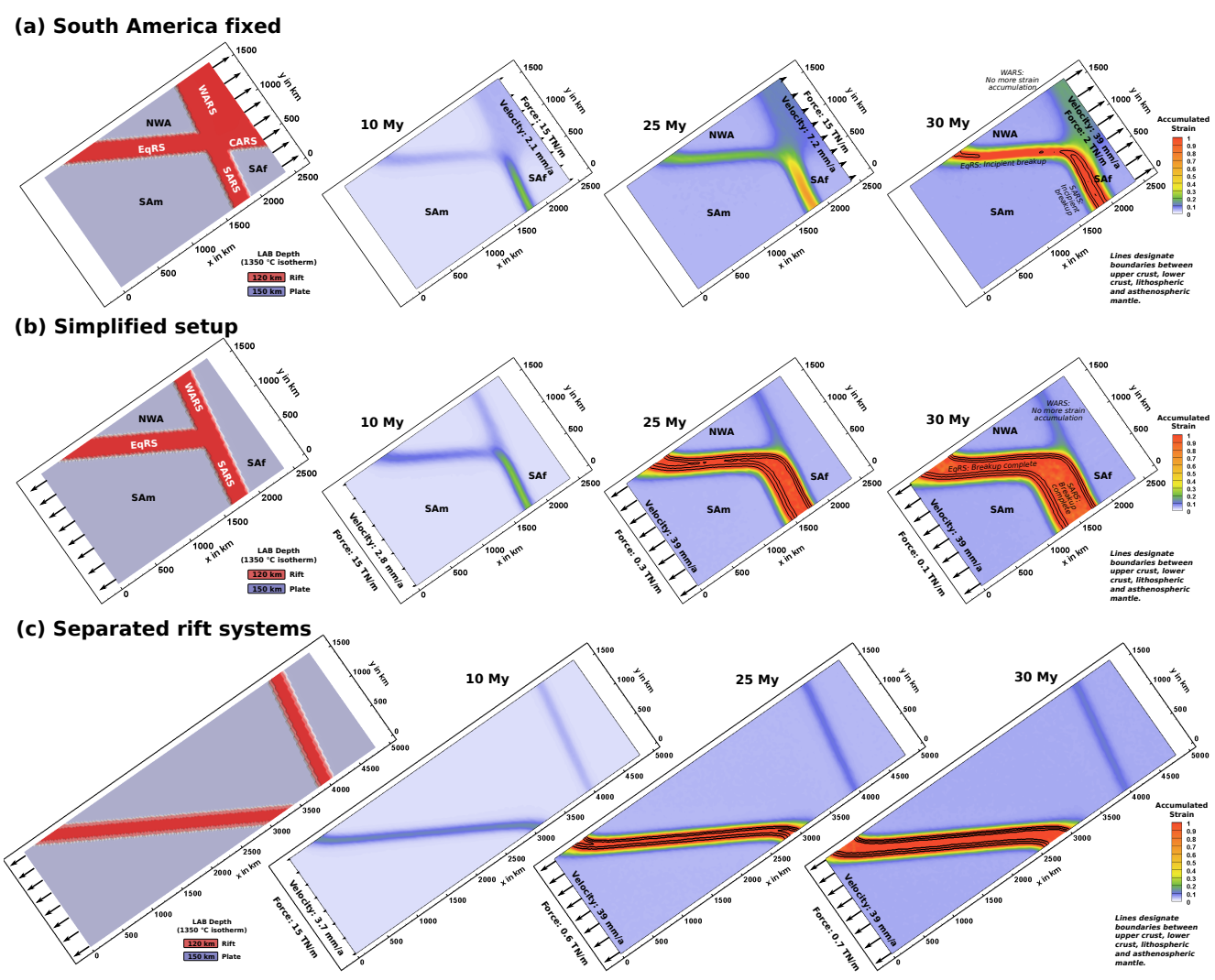

Figure DR1: Alternative model scenarios. First image in each line shows the model setup, subsequent images the model's evolution in time in terms of accumulated plastic strain. Rift velocities are depicted by black arrows, the respective value of velocity and force is indicated at the model boundary.

setup leads to nearly identical model evolution with a slow initial rift phase followed by severe acceleration after $27 \mathrm{My}$. The similarity between this model and the one shown in Figure 3 (main article) means that asthenospheric flow does not affect our experiments. It also shows that our results are independent of the mantle reference frame that was chosen for the plate tectonic reconstruction.

The complex intersection of the Central African Rift System (CARS) with the West African Rift System (WARS) has been introduced in our numerical setup through a diffuse wide initial rift zone at the North-East Model side. In order to estimate the impact of this wide rift zone on the model dynamics, we conducted an experiment where this zone of complexity was neglected. Only WARS, SARS and EqRS are accounted for with identical initial rift width of $200 \mathrm{~km}$ (Supplementary Figure 1-b). The general model evolution is very similar to the model of Figure 3 (main article), but the timing of the individual 
phases is different. The simplified model experiences strong plate acceleration already after 17 My instead of 27 My like in the original model. The reason for this behavior lies in the dynamics of rift competition. If two competing rifts are similarly strong, like in the reference model where the obliquity of the EqRS is balanced by the wider weak zone of the WARS, each of the rift arms will acquire similar amounts of strain. If the lithosphere of one arm is strengthened significantly (here: WARS), the other rift (EqRS) will accumulate strain at a higher rate leading to more efficient weakening in this rift arm and earlier break-up than in the reference model.

We reduce model complexity by omitting the rift triple-junction. Note that the length of the model has to be enlarged in order to avoid contact of the rift branches. The highly oblique rift arm reaches break-up after $28 \mathrm{My}$. The model evolution is nearly identical to the previous scenario. These experiments show that our conclusions do not depend on details of the setup.

For even more simplified, fundamental 2D experiments with a single rift zone, we refer to the Section 4.3 of Brune et al. (2012). These experiments show the same speed-up for extension rates if force boundary conditions are applied.

\section{Plate tectonic reconstructions}

The set of paleo-tectonic maps in Mercator projection shows the modelled plate kinematic evolution of the Equatorial Atlantic region from $140 \mathrm{Ma}$ to $100 \mathrm{Ma}$ in $1 \mathrm{Myr}$ time intervals in a southern Africa-fixed reference frame. The last page of this PDF contains a map legend.

Abbreviations used in maps:

- Lithospheric plates: NEA - Northeast Africa, NWA - Northwest Africa, SAf - Southern Africa, SAm - South America.

- Minor rigid plates: BPB - Borborema Province Block (NE Brazil), Jos - Jos Subplate in northern Nigeria, SLC - So Luis Craton.

- Present-day submarine features: DeR - Demarara Rise, GPl. - Guinea Plateau.

- Basins (red font, white background in annotation indicates active extension, grey background indicates tectonic quiescence at reconstruction time): BarB - Barreirinhas Basin, BeT - Benoue Trough, CdIGR - Cte dIvoire/Ghana Ridge, D/D B. - Doba/Doseo Basins, DGB - Deep Ghanaian Basin, FdA - Foz do Amazon, IuB - Iullemmeden Basin, KB - Keta/Togo/Benin Basin, MarB - Maraj Basin, PoT - Potiguar Basin, RTJ - Recncavo/Tucano/Jatoba Basins, Gao T. - Gao Trough

All reconstructions are show with southern Africa (SAf) held fixed in present-day coordinates. Reconstruction timescale is hybrid absolute timescale as used in Heine et al. (2013). Surface outcrops of Proterozoic and Jurassic/Cretaceous-aged units are derived 
from the US Geological Survey World Energy Project (denoted as USGS in map legend; Persits et al., 2002) and the Geological Map of the World (denoted as CGMW in map legend; Commission for the Geological Map of the World, 2009)

Data accompanying the paper (including the full plate kinematic model for use in GPlates can be downloaded as supplementary material from the Solid Earth journal website (http://dx.doi.org/10.5194/se-4-215-2013) or the Datahub of the OpenKnowledge Foundation at: http://datahub.io/dataset/southatlanticrift.

Light gray dashed lines are present-day $5^{\circ}$ graticule

\section{References}

Artemieva, I. M., Global $1^{\circ} \times 1^{\circ}$ thermal model TC1 for the continental lithosphere: Implications for lithosphere secular evolution, Tectonophysics, 416, 245-277, doi:10.1016/j.tecto.2005.11.022, 2006.

Brune, S., A. A. Popov, and S. V. Sobolev, Modeling suggests that oblique extension facilitates rifting and continental break-up, Journal of Geophysical Research, 117(B8), B08,402, doi:10.1029/2011JB008860, 2012.

Commission for the Geological Map of the World, Geological Map Of The World At 1: 50000000 And 1:25 000000 Scales, Commission for the Geological Map of the World, 77, rue Claude-Bernard 75005 Paris, France, 2009.

Gleason, G. C., and J. Tullis, A Flow Law for Dislocation Creep of Quartz Aggregates Determined with the Molten-Salt Cell, Tectonophysics, 247(1-4), 1-23, 1995.

Heine, C., J. Zoethout, and R. D. Müller, Kinematics of the South Atlantic rift, Solid Earth, 4(2), 215-253, doi:10.5194/se-4-215-2013, 2013.

Hirth, G., and D. L. Kohlstedt, Rheology of the upper mantle and the mantle wedge: A view from the experimentalists, Geophysical Monograph, 138, 83-105, 2003.

Persits, F. M., T. S. Ahlbrandt, M. L. Tuttle, R. R. Charpentier, M. E. Brownfield, and K. I. Takahashi, Surficial geology of Africa (geo7_2ag), Open-File Report OFR-97-470-A, U.S. Geological Survey, Central Energy Resources Team, 2002.

Popov, A. A., and S. V. Sobolev, SLIM3D: A tool for three-dimensional thermomechanical modeling of lithospheric deformation with elasto-visco-plastic rheology, Phys. Earth Planet. Int., 171(1-4), 55-75, doi:10.1016/j.pepi.2008.03.007, 2008.

Tommasi, A., and A. Vauchez, Continental rifting parallel to ancient collisional belts: an effect of the mechanical anisotropy of the lithospheric mantle, 185, 199-210, doi:10.1016/S0012-821X(00)00350-2, 2001. 
Wilks, K. R., and N. L. Carter, Rheology of Some Continental Lower Crustal Rocks, Tectonophysics, 182(1-2), 57-77, doi:10.1016/0040-1951(90)90342-6, 1990.

Ziegler, P. A., and S. A. P. L. Cloetingh, Dynamic processes controlling evolution of rifted basins, Earth Sci. Rev., 64(1-2), 1-50, doi:10.1016/S0012-8252(03)00041-2, 2004. 

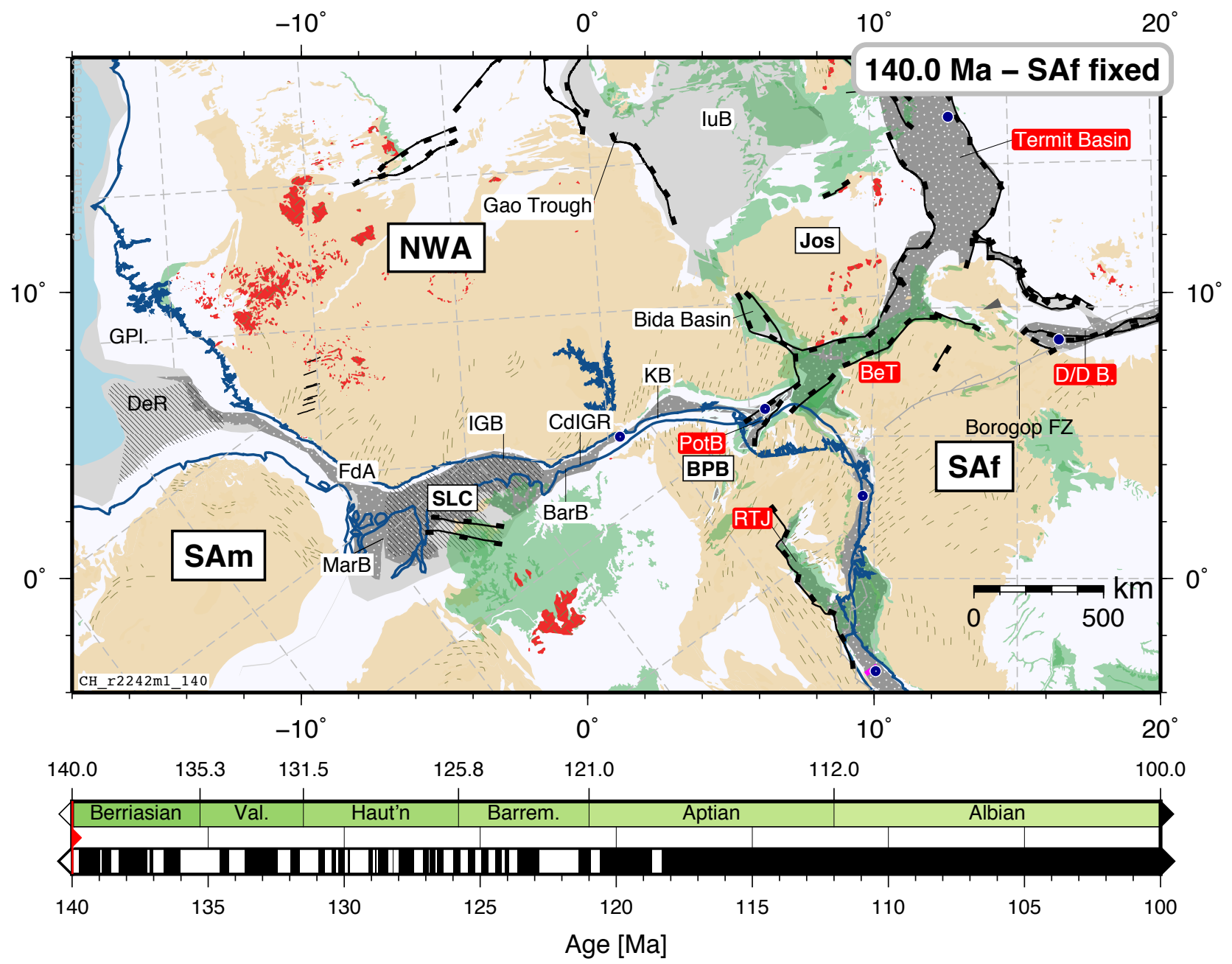


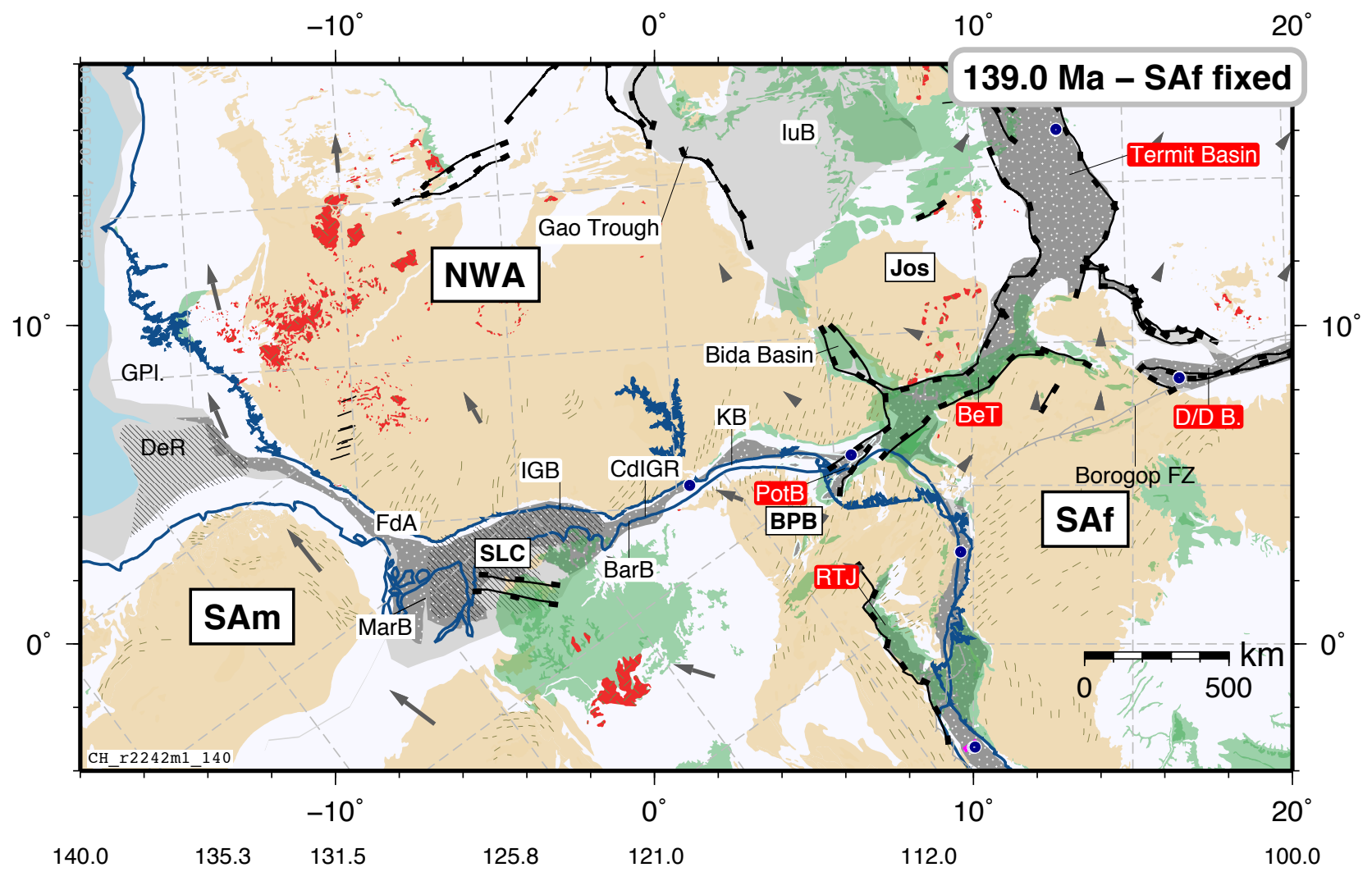

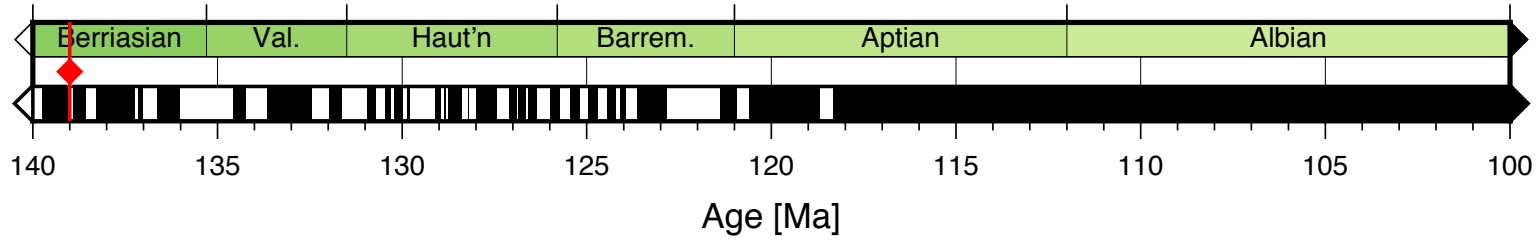




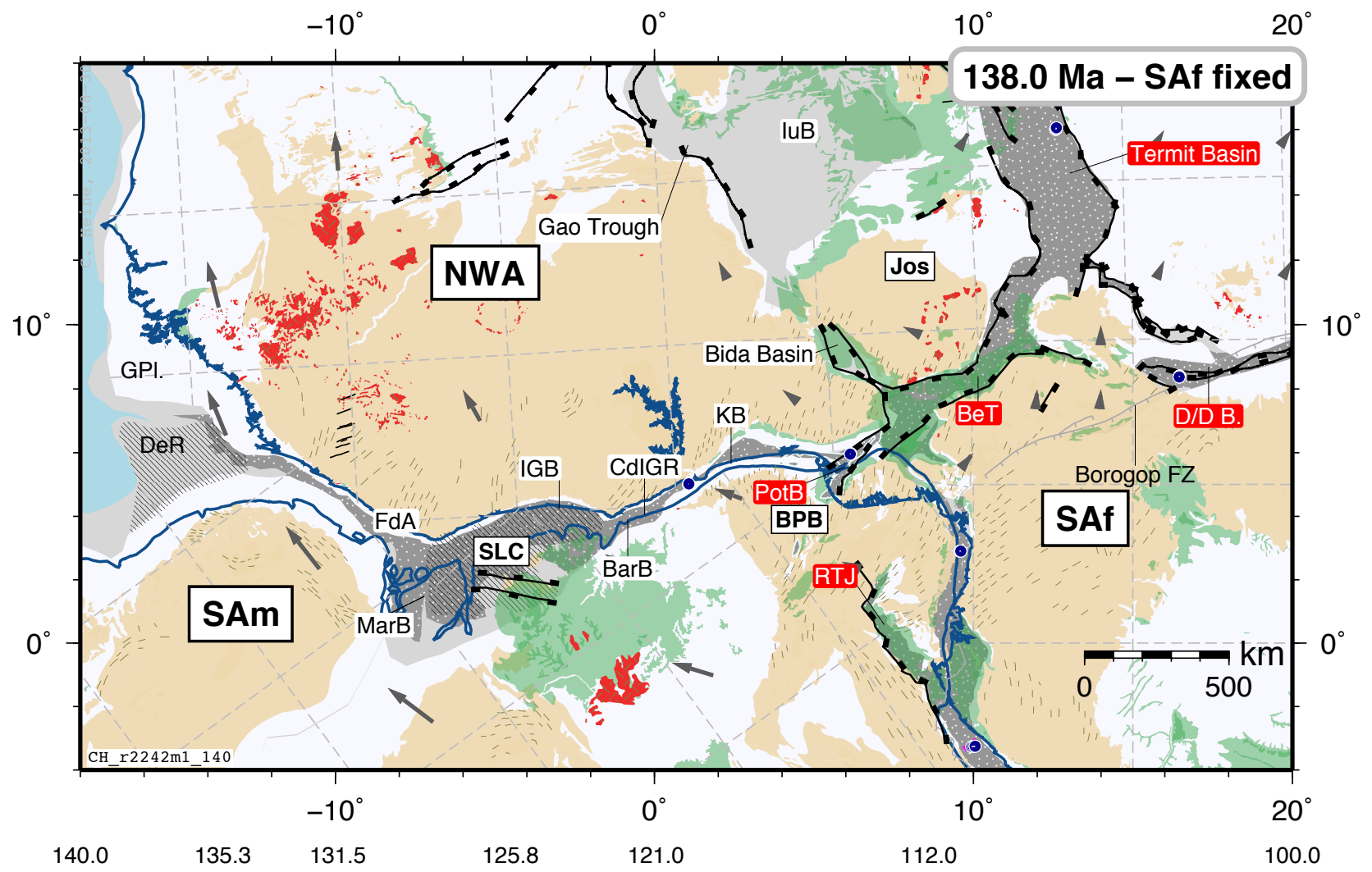

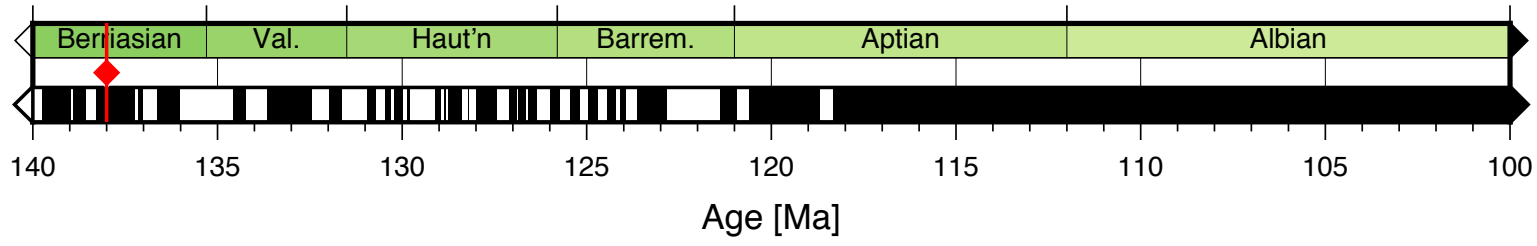




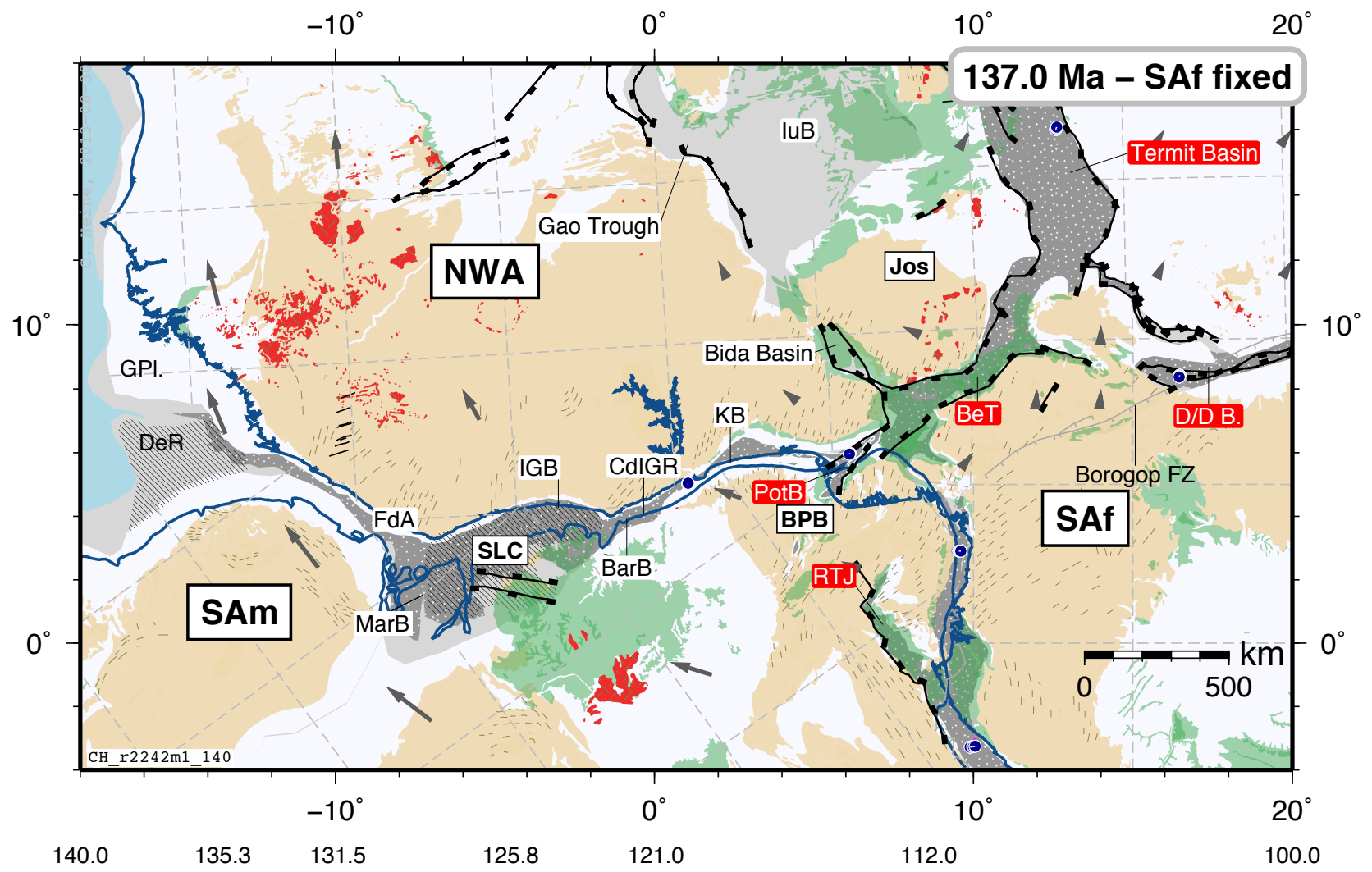

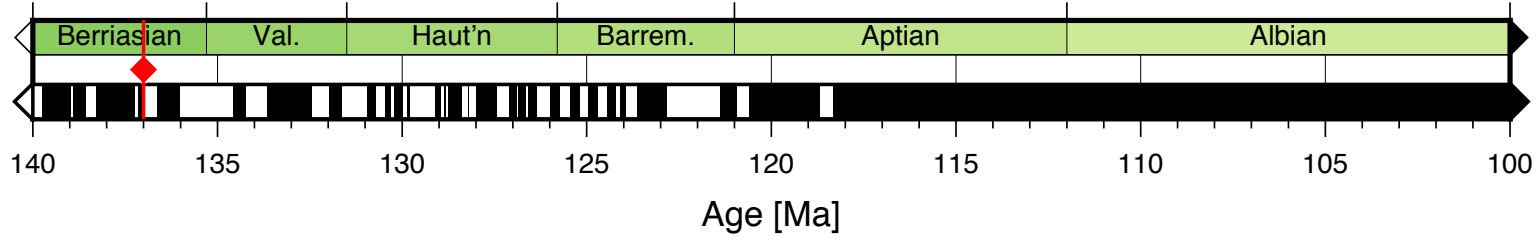




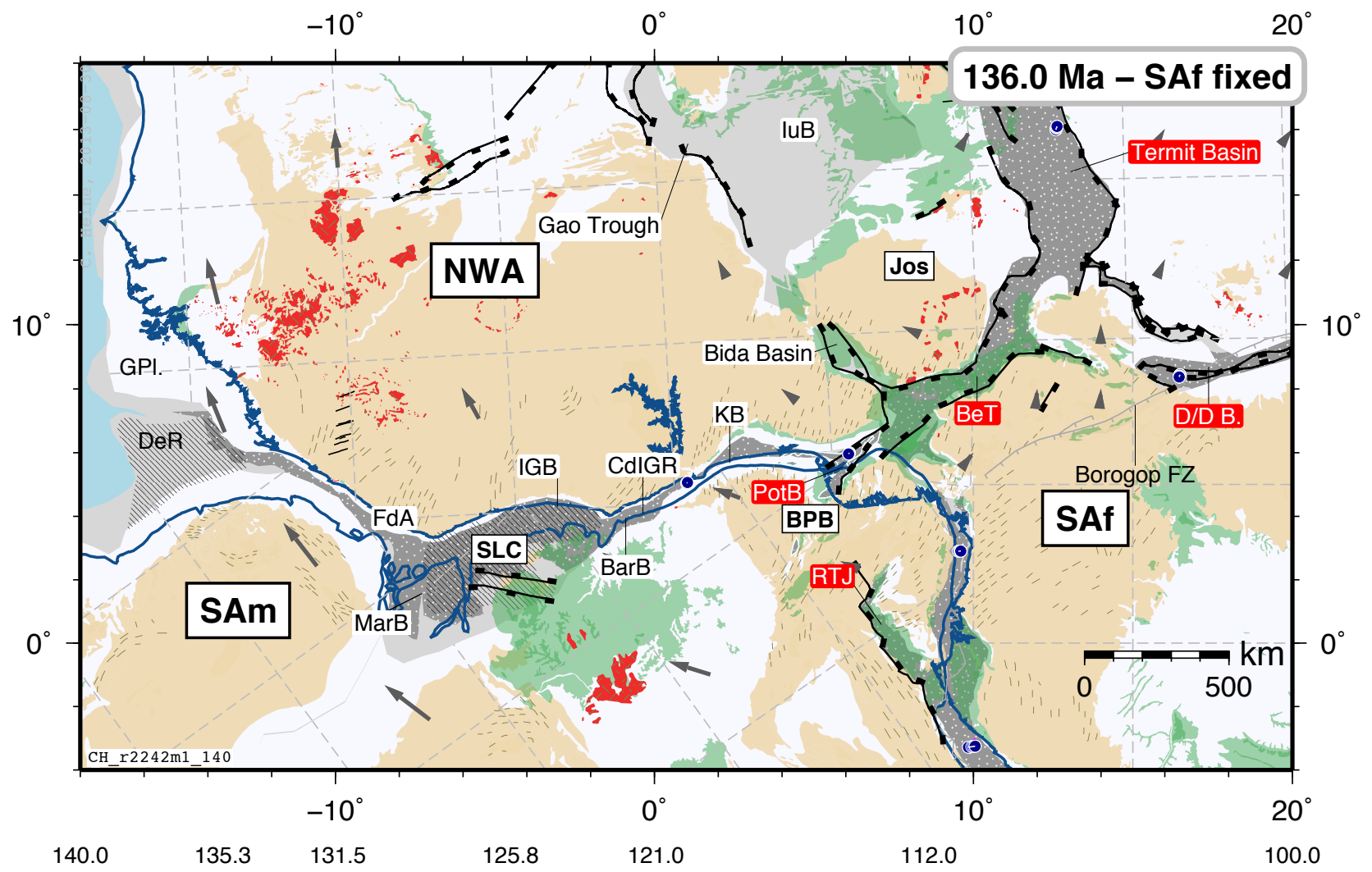

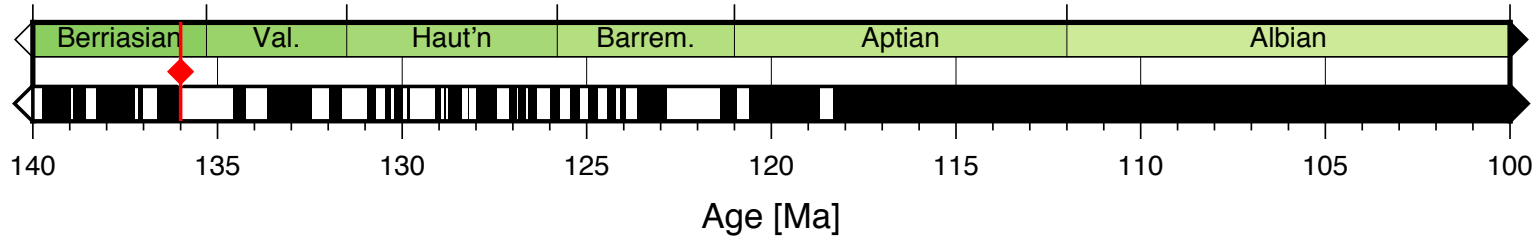



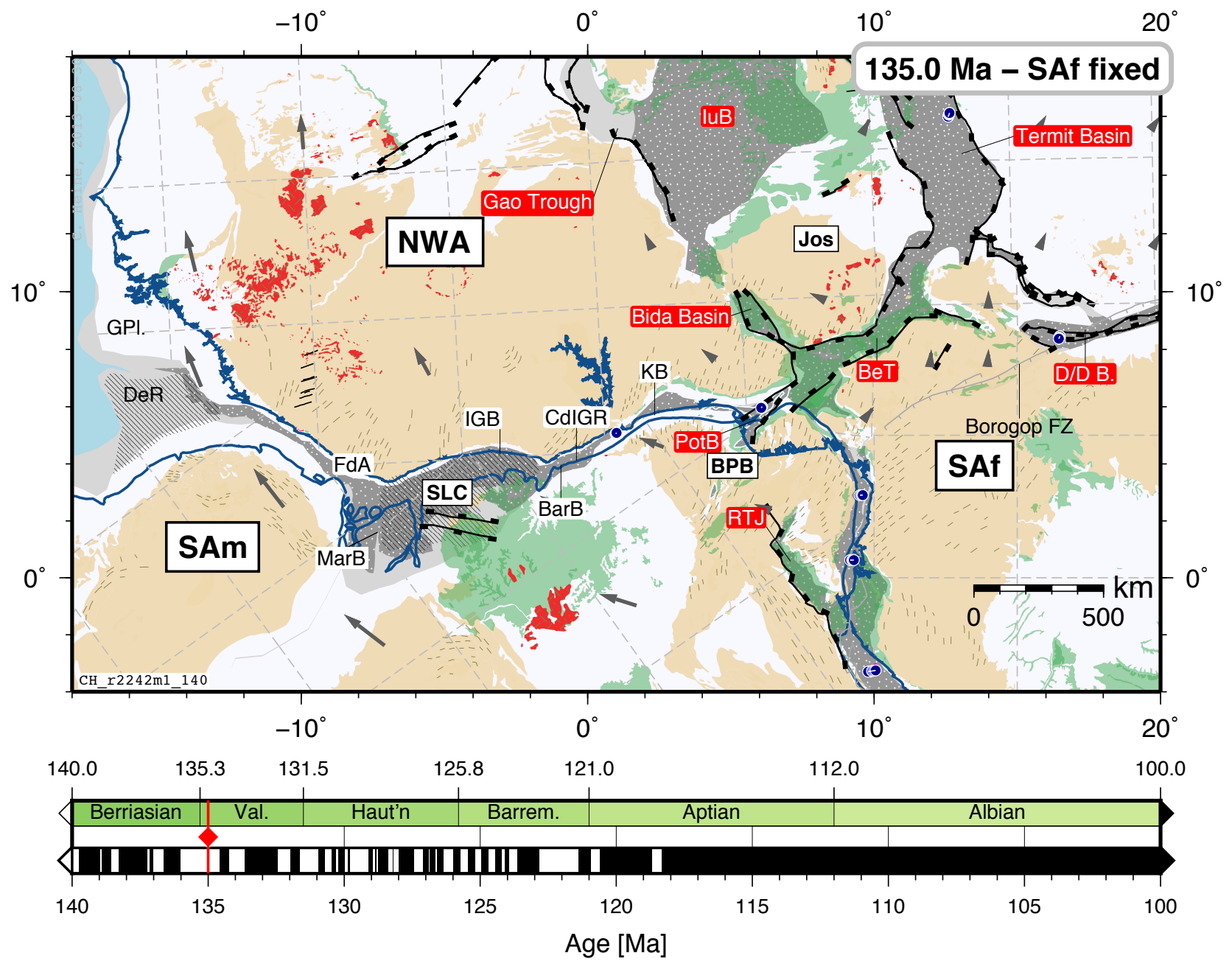


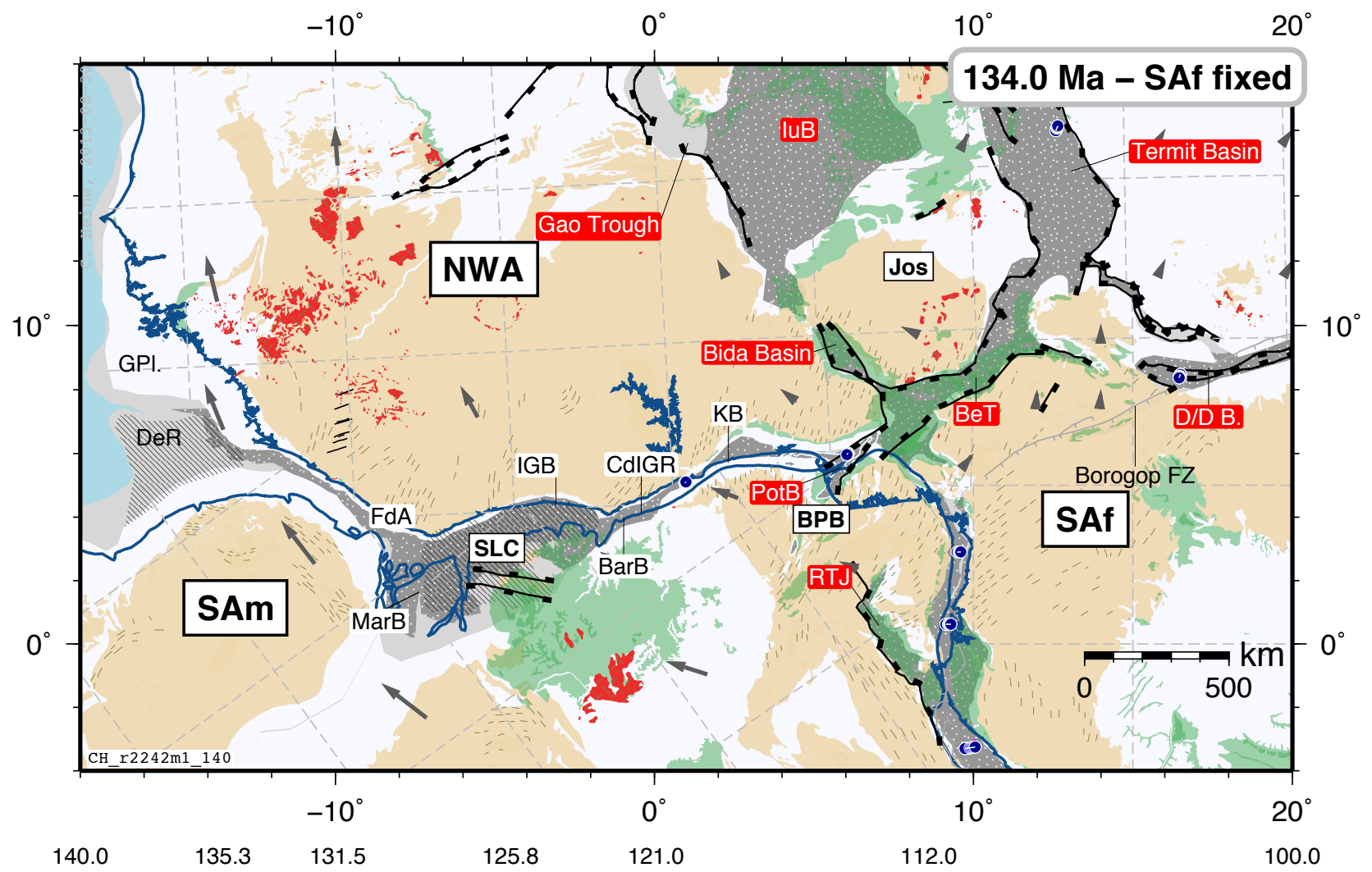

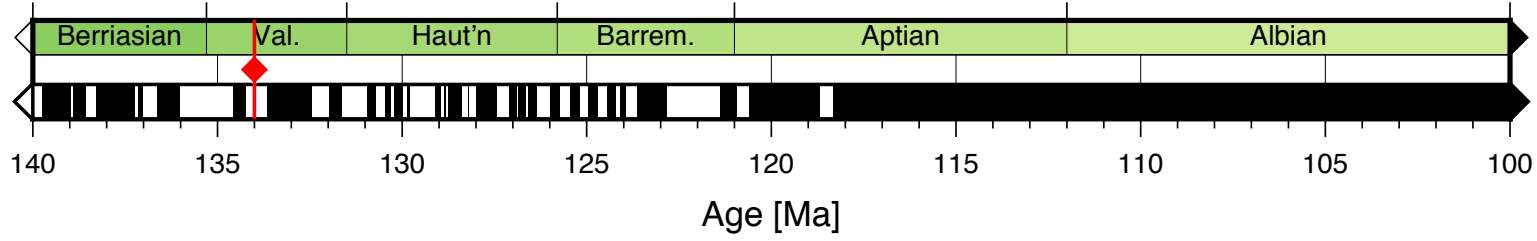




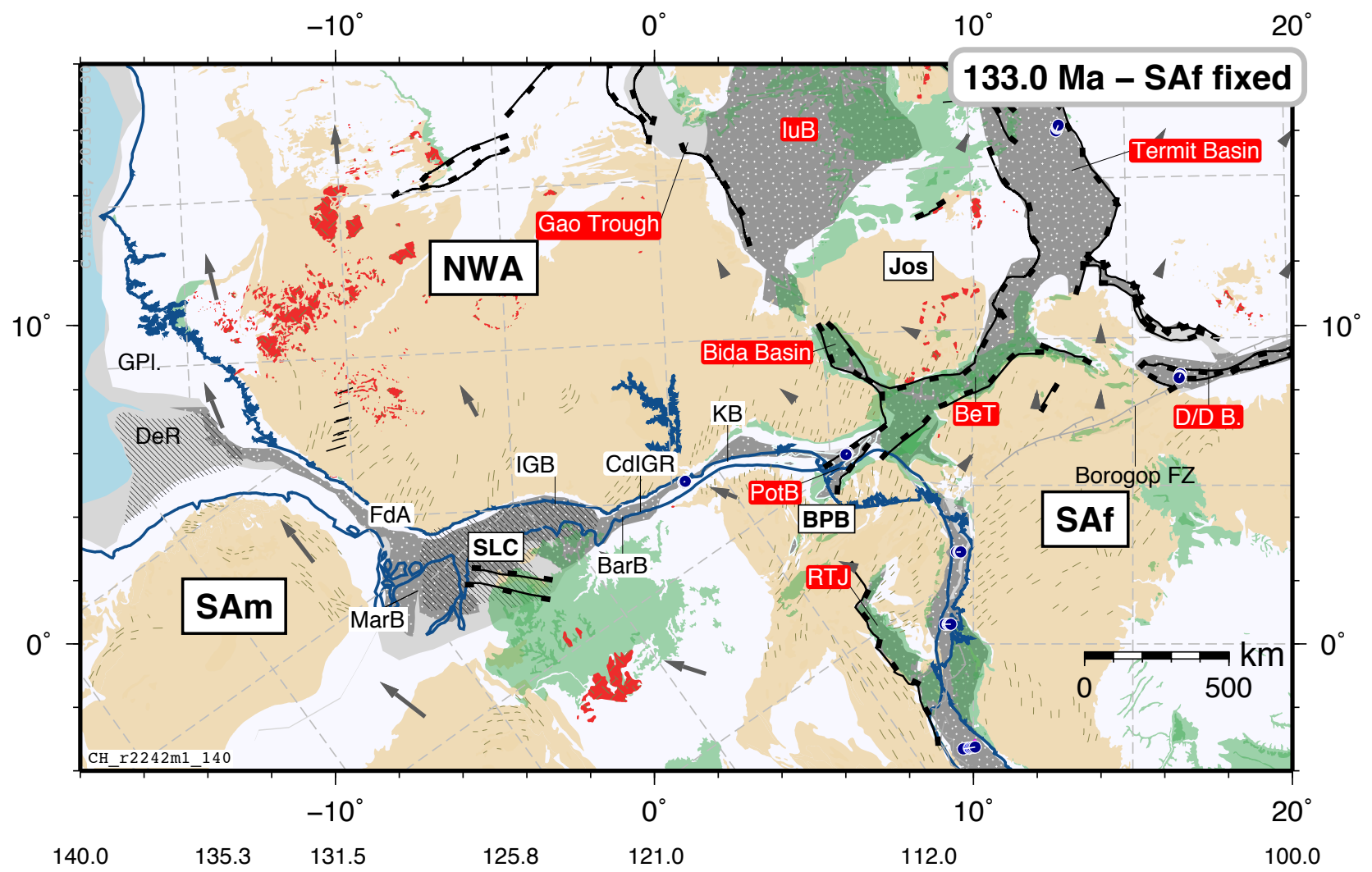

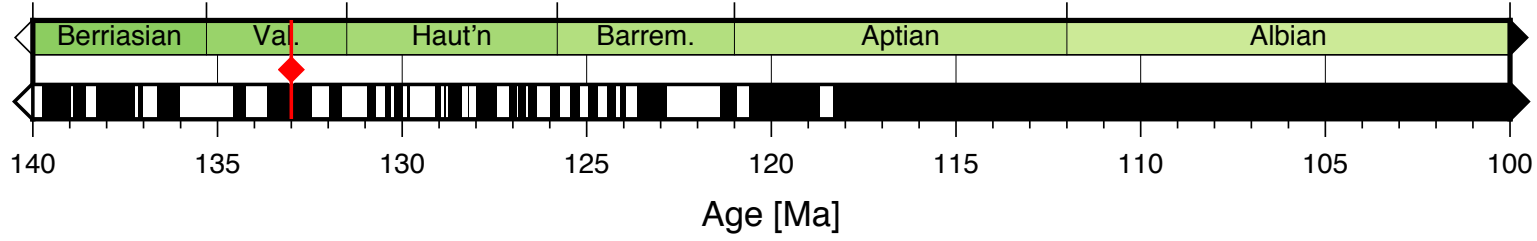




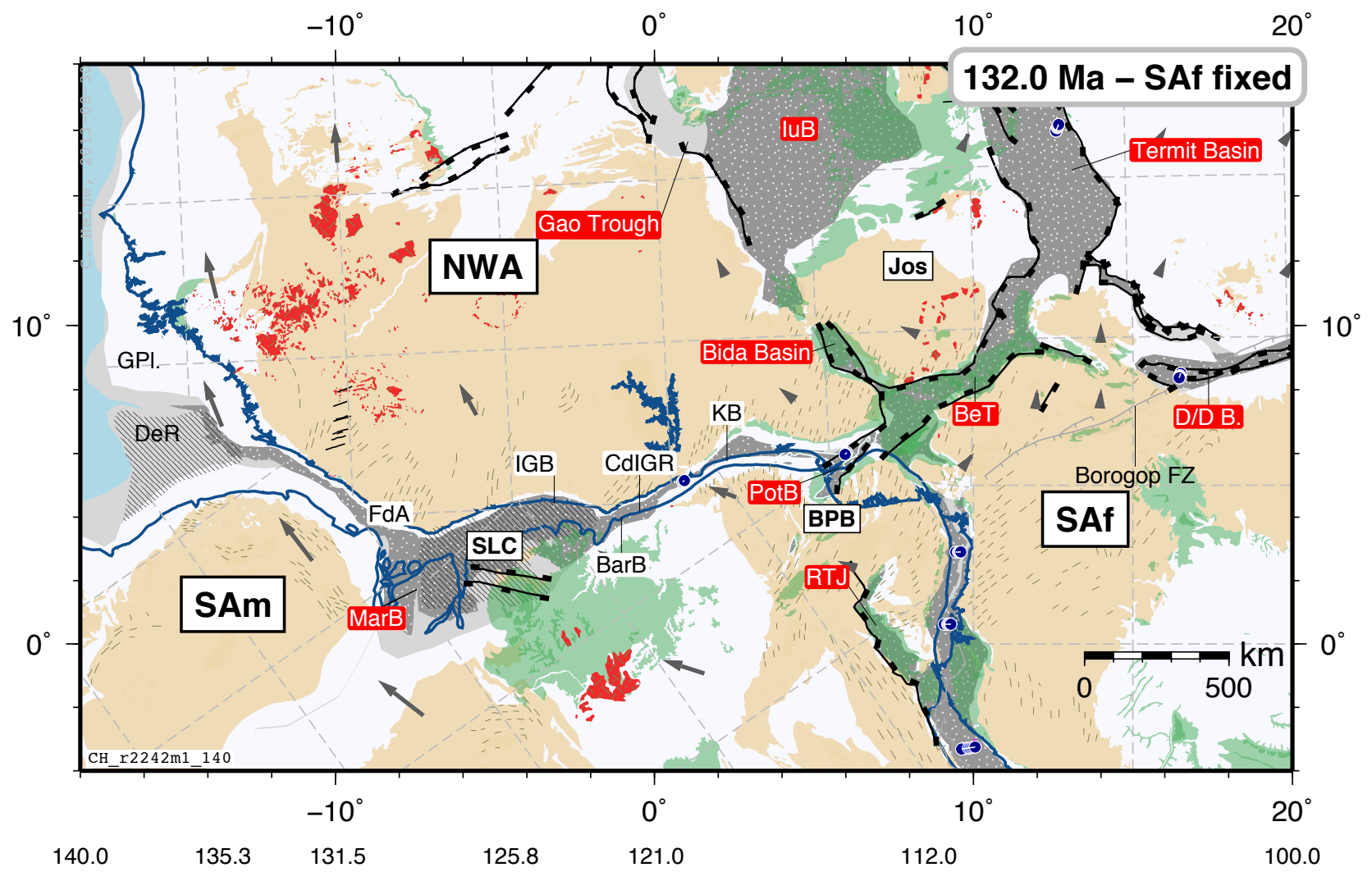

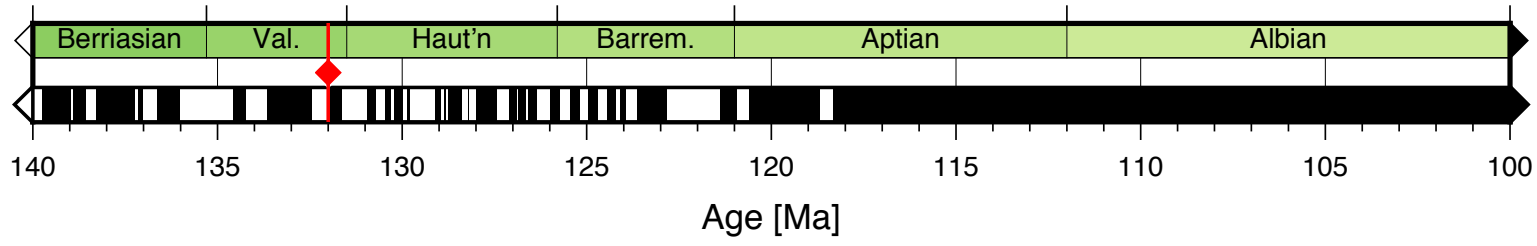




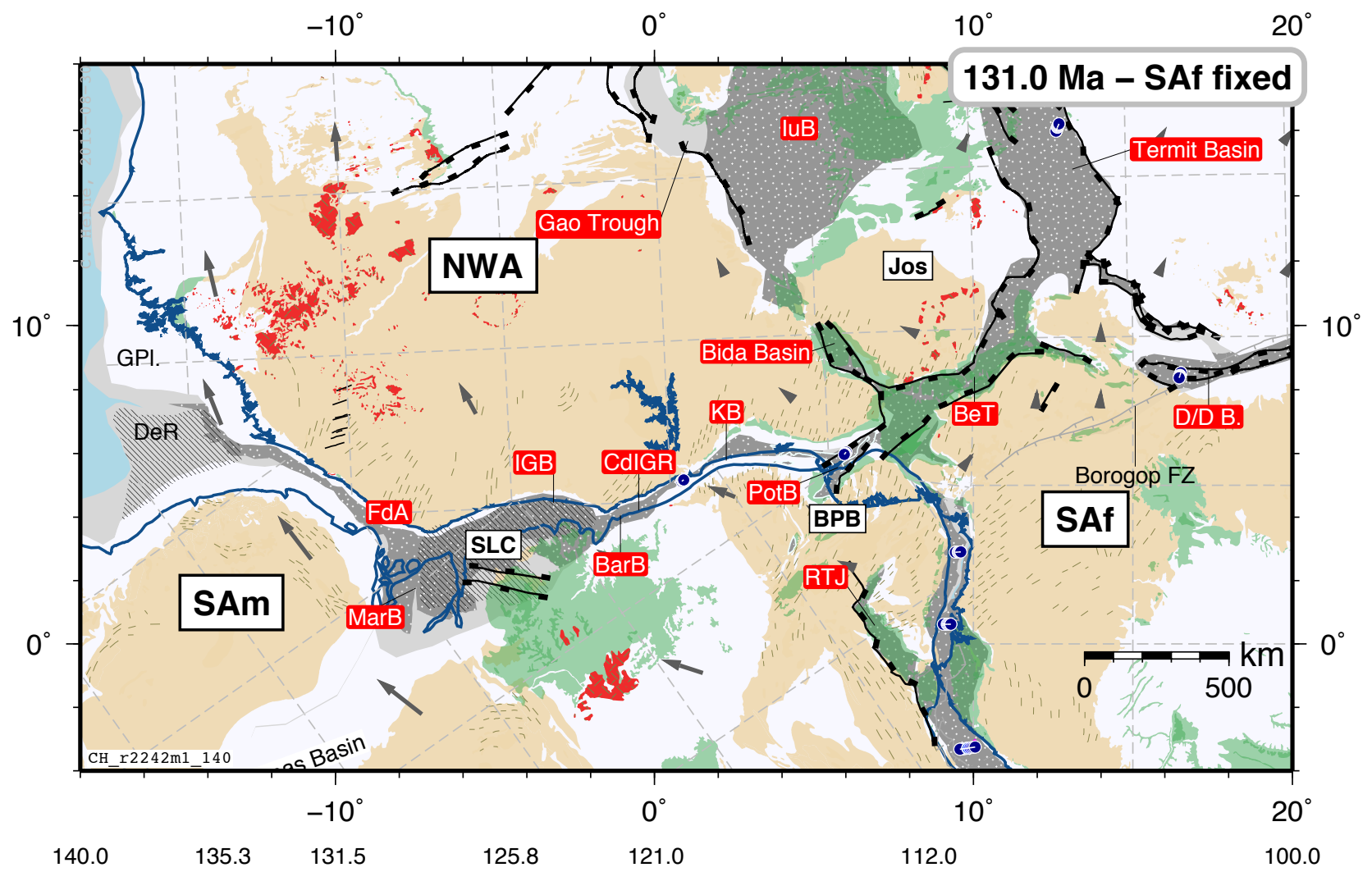

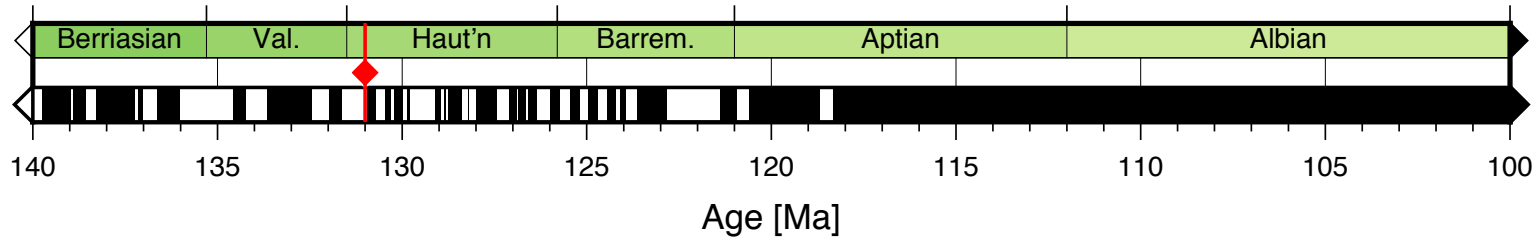




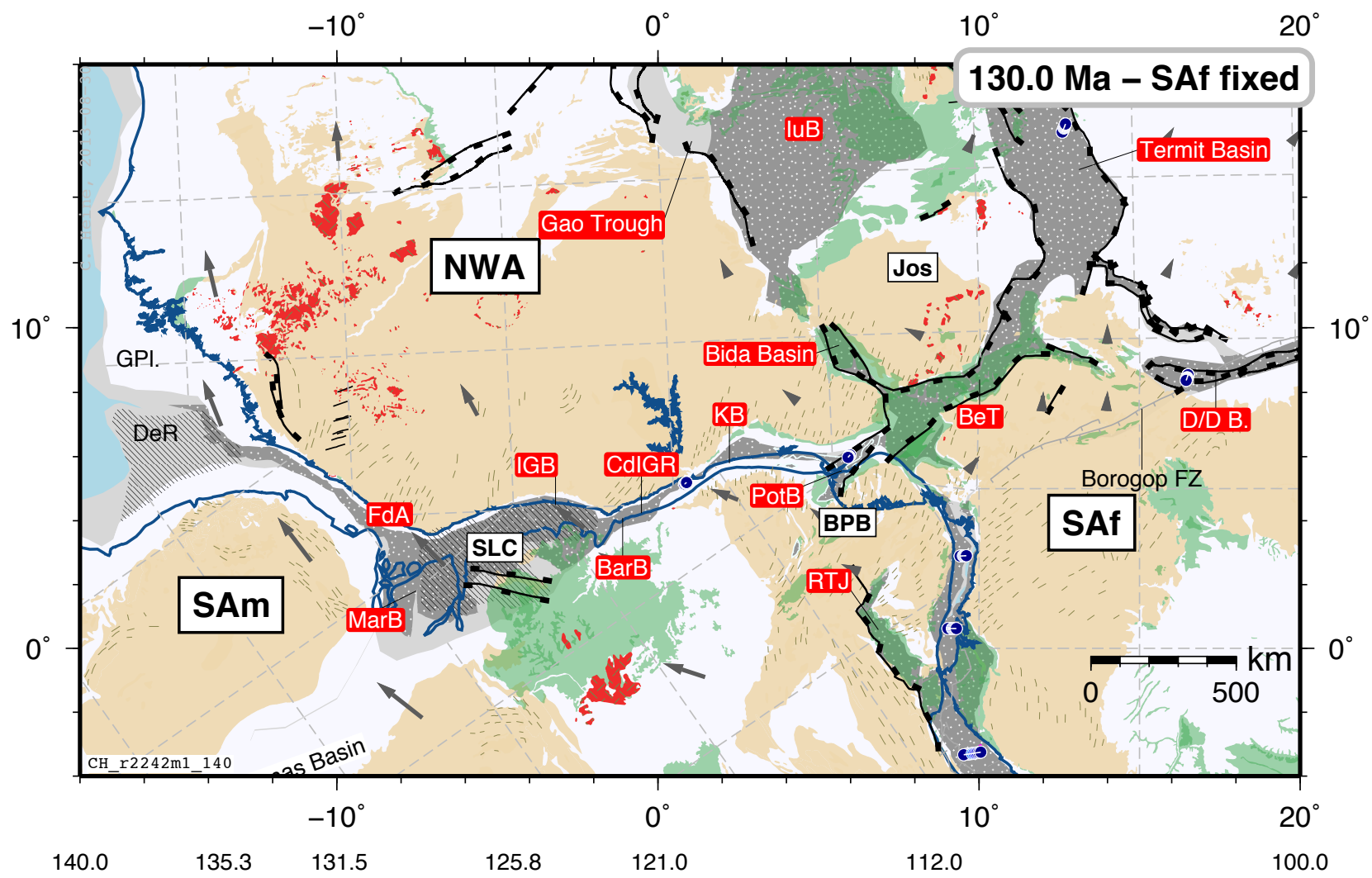

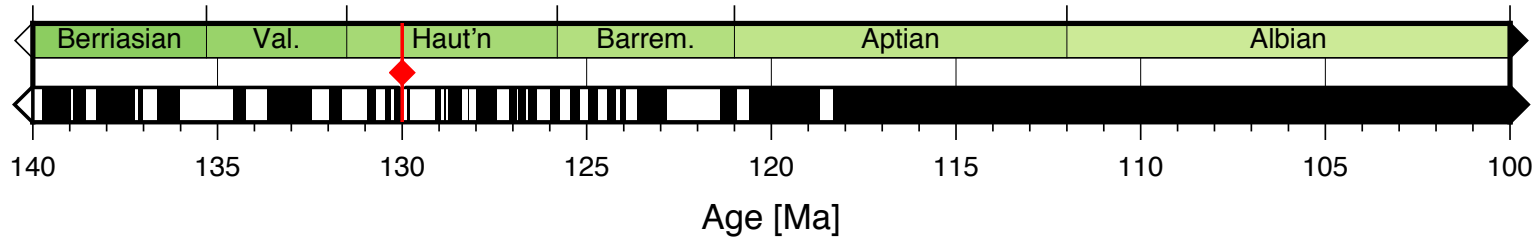




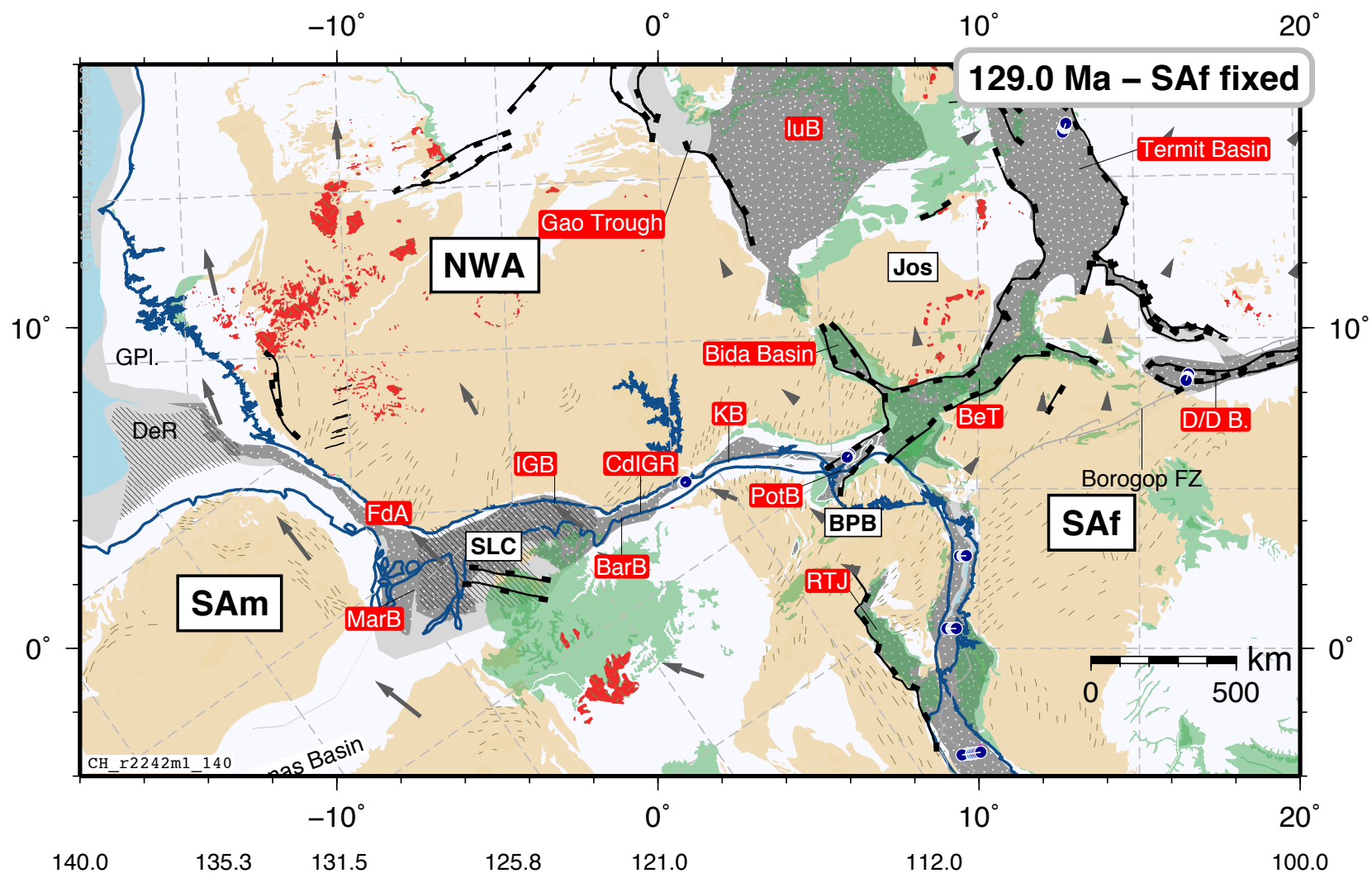

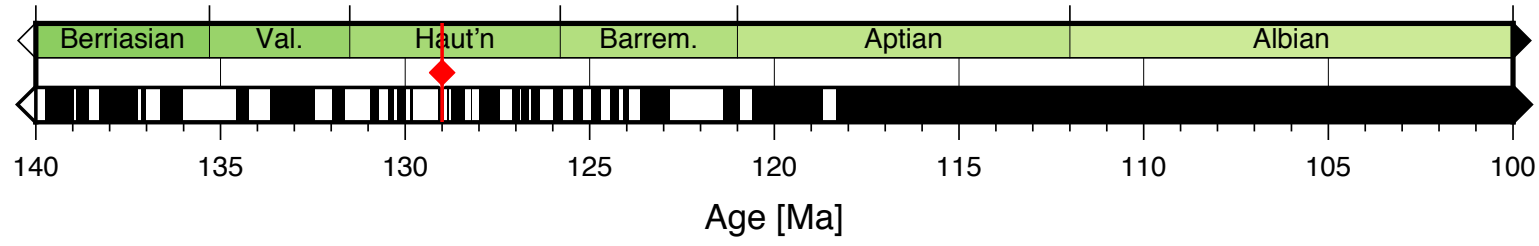




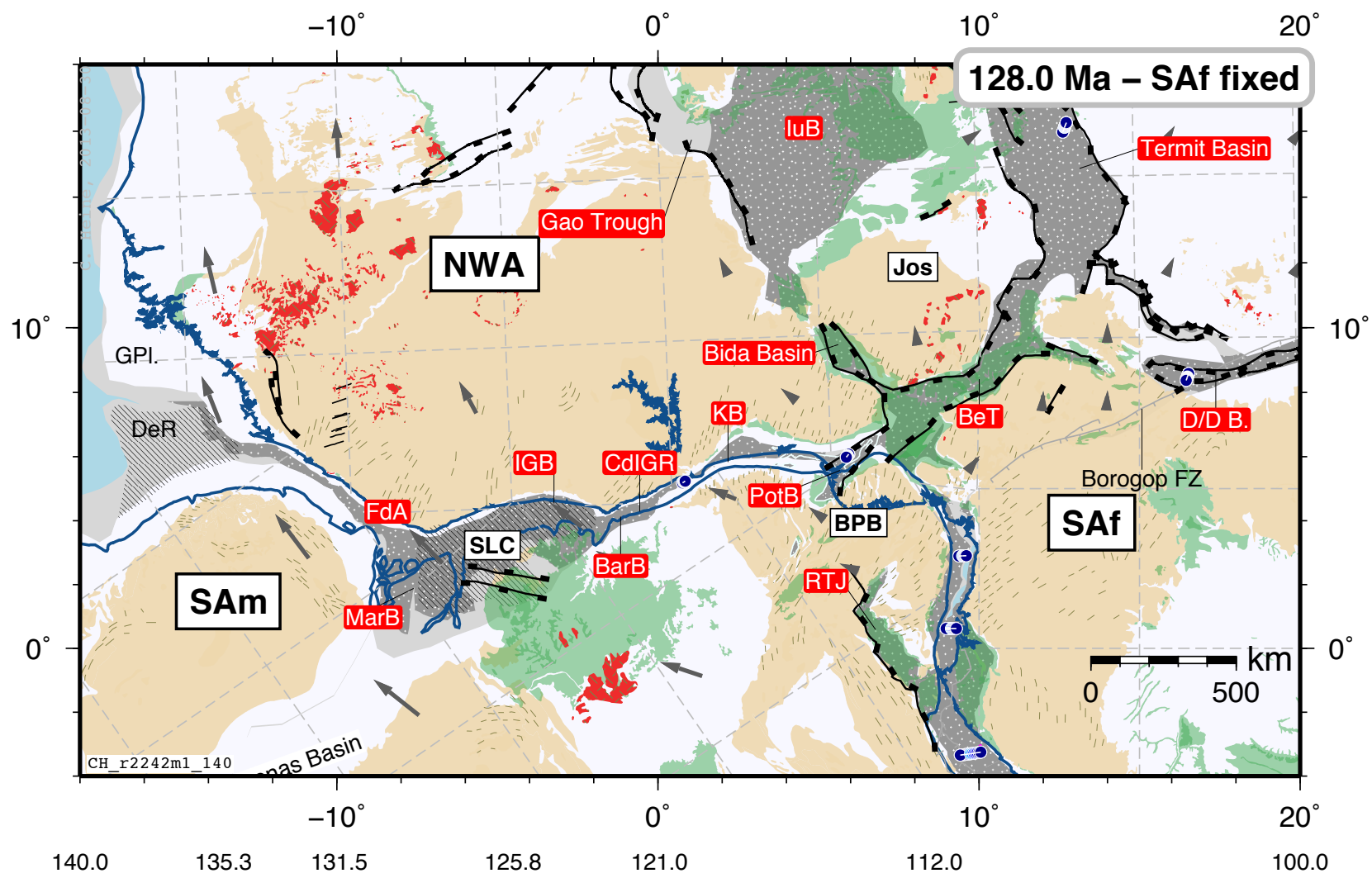

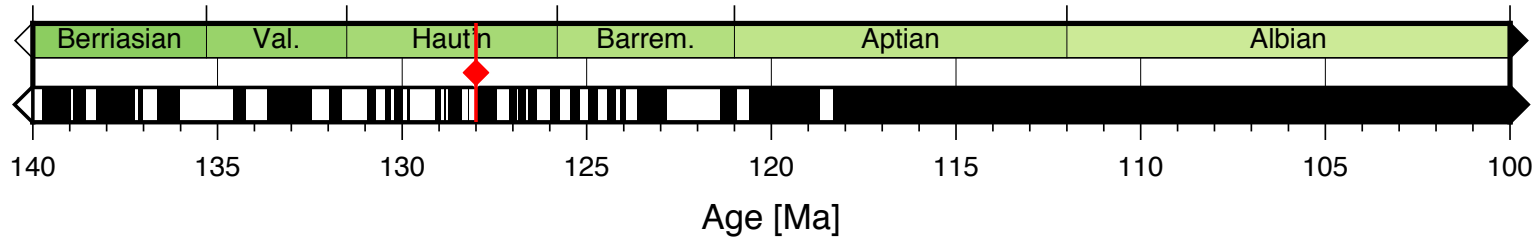




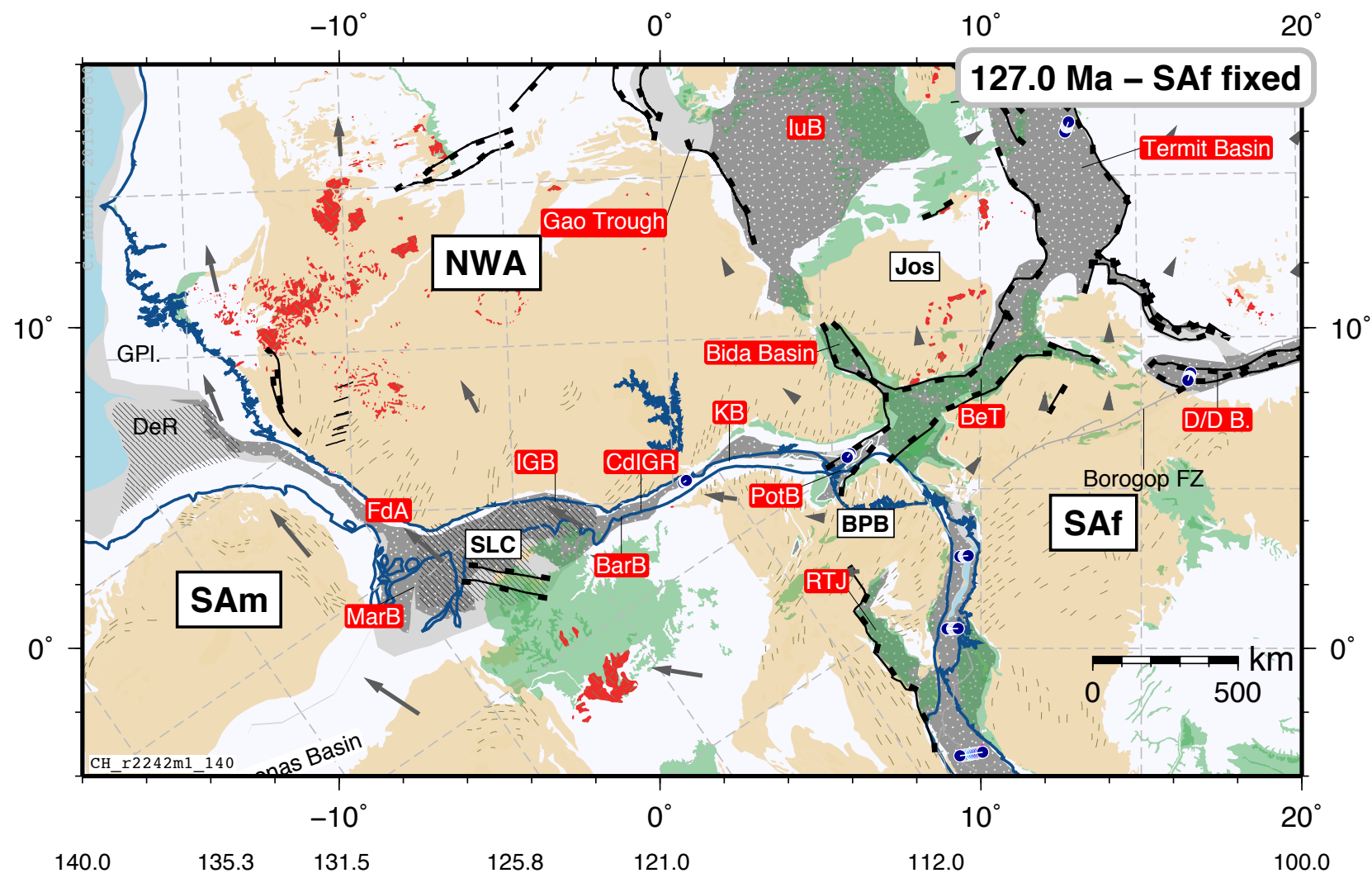

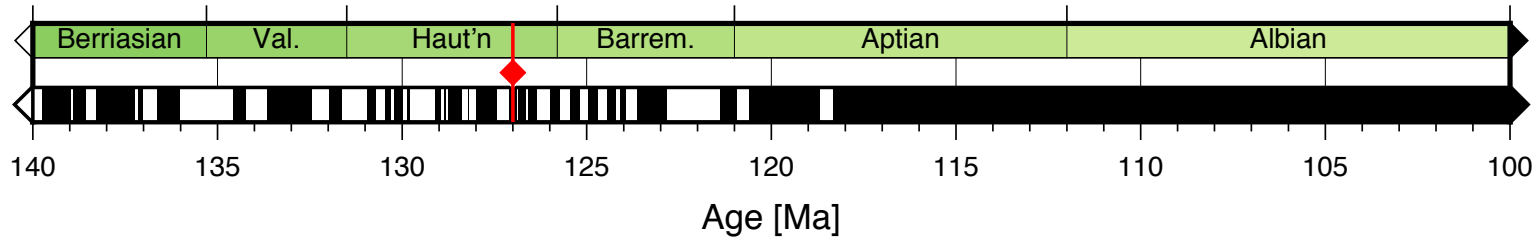




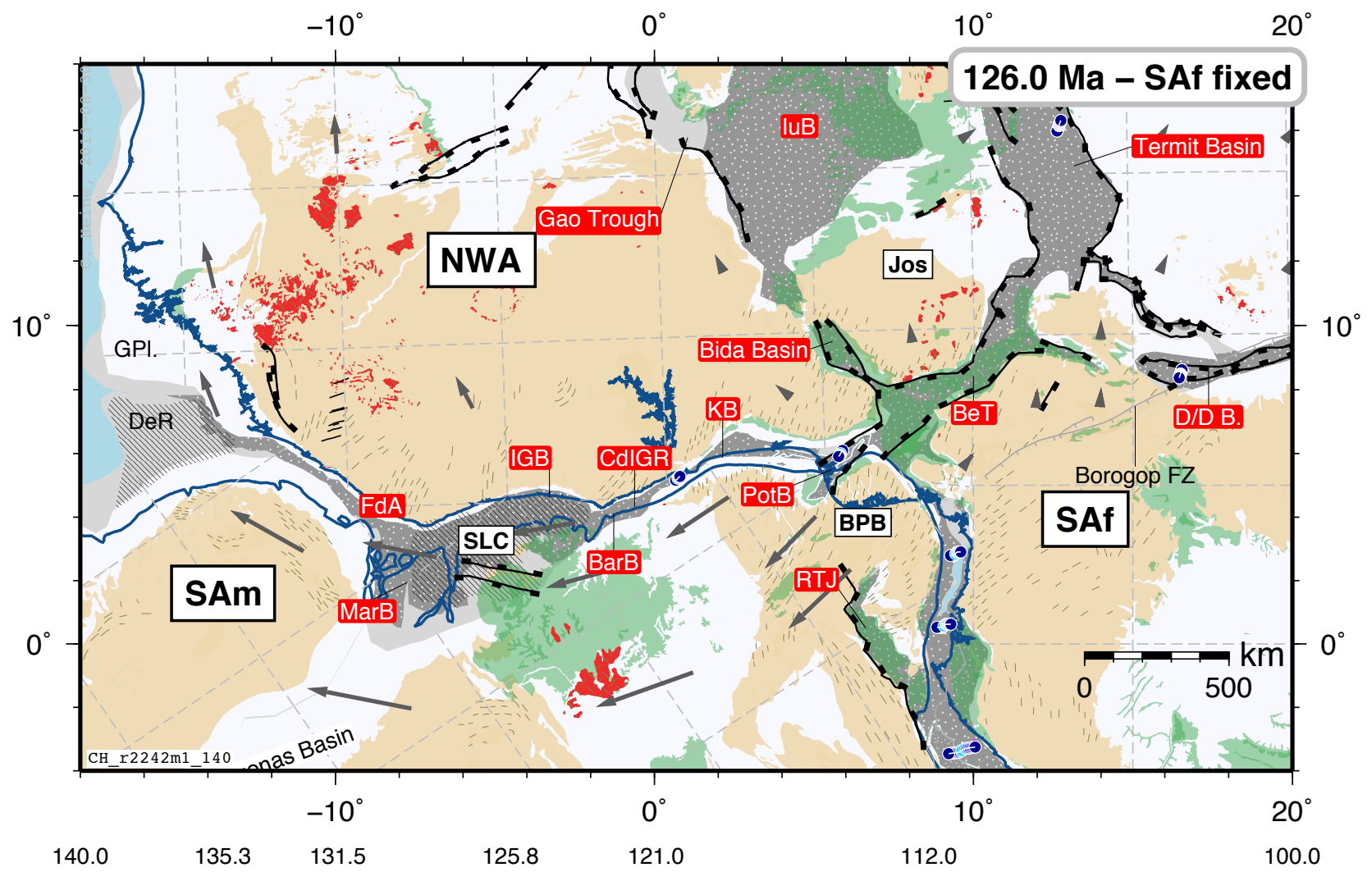

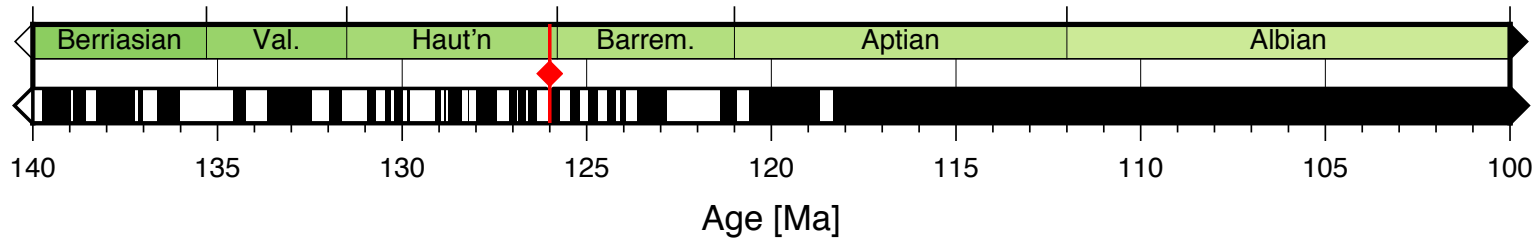




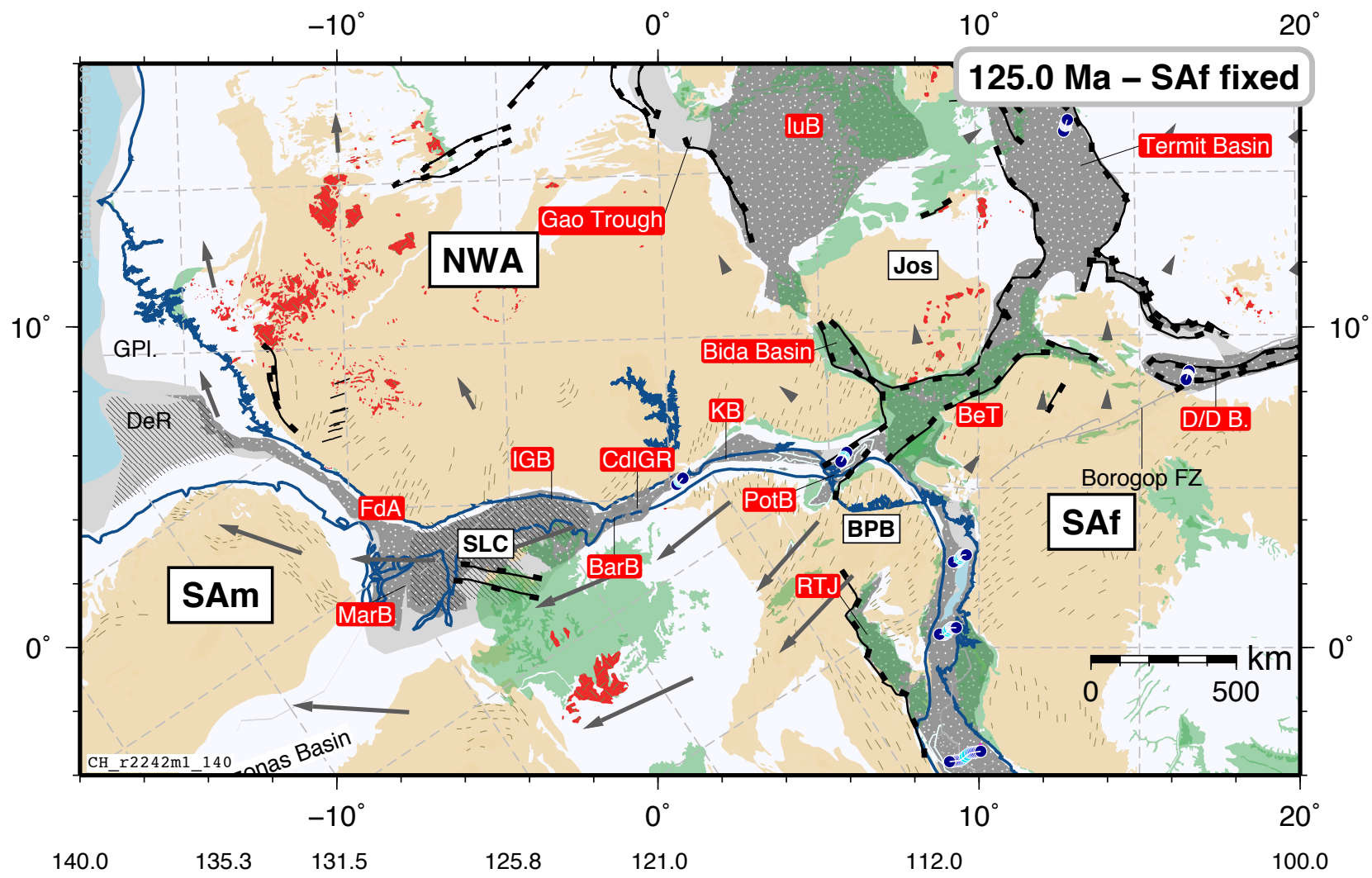

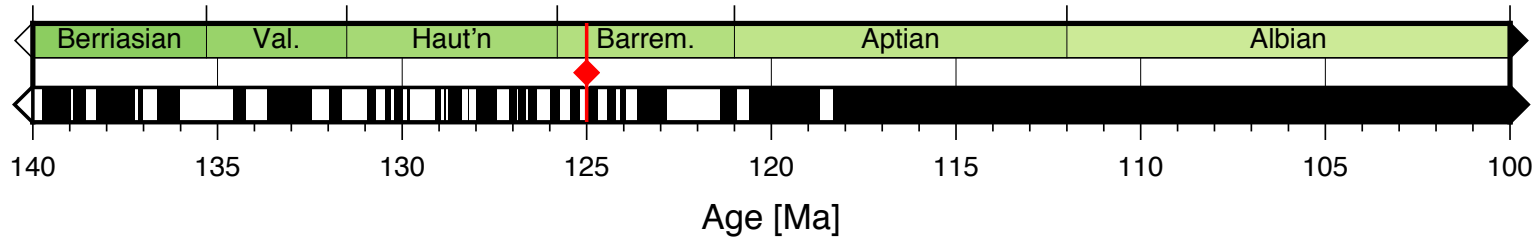




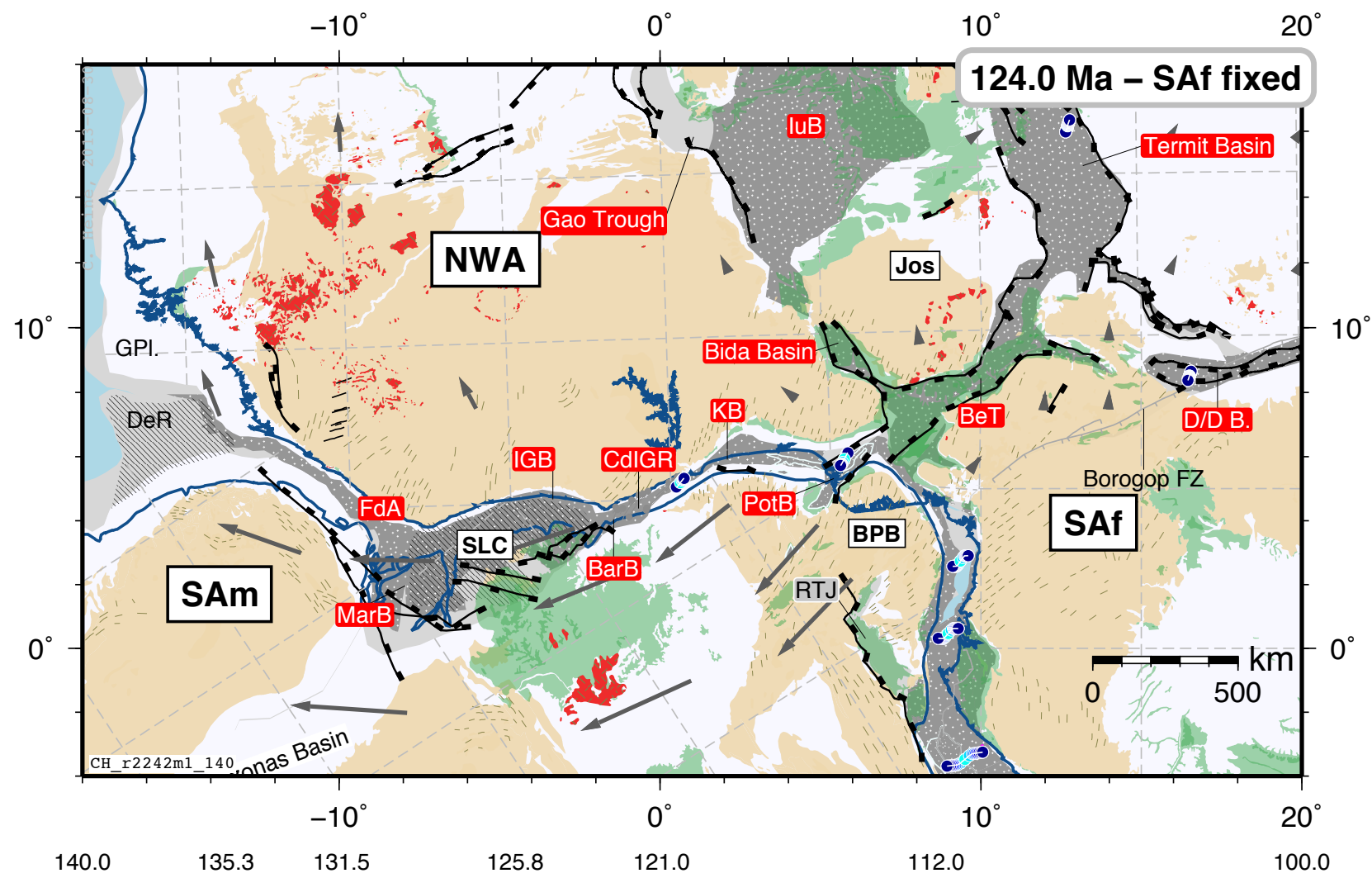

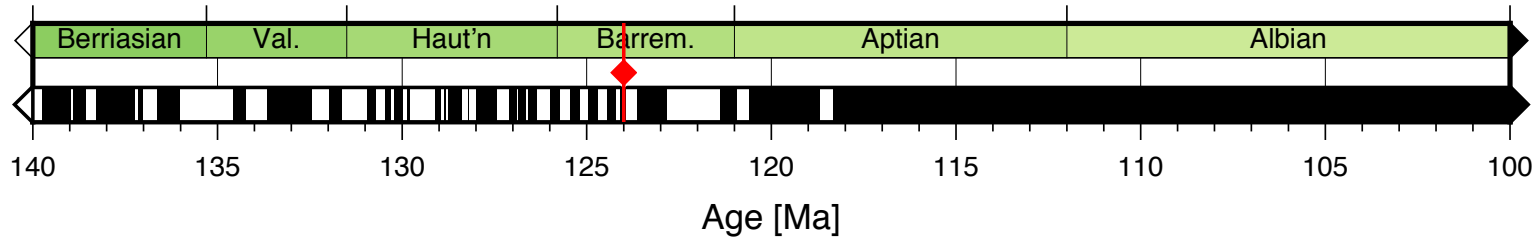




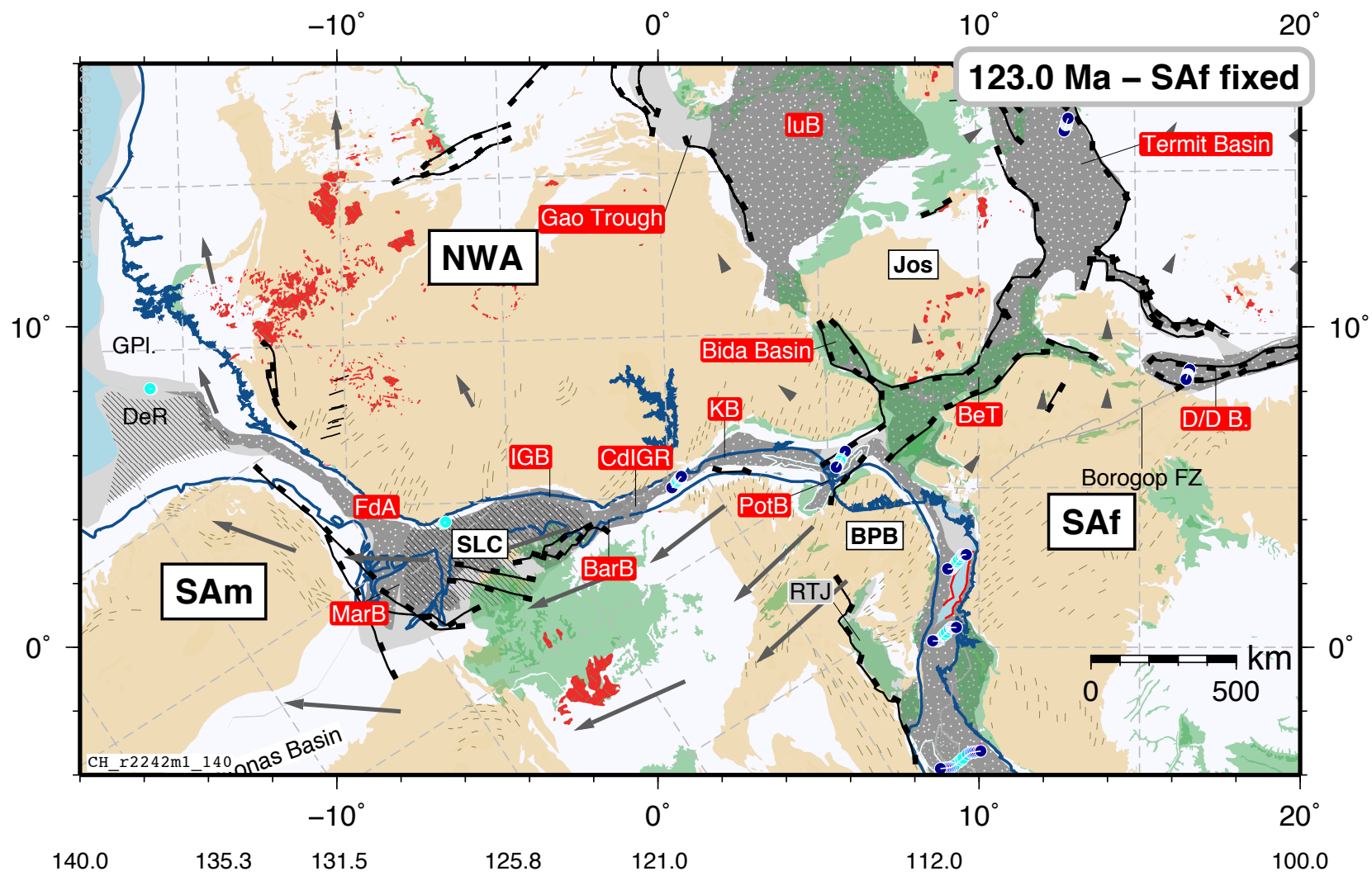

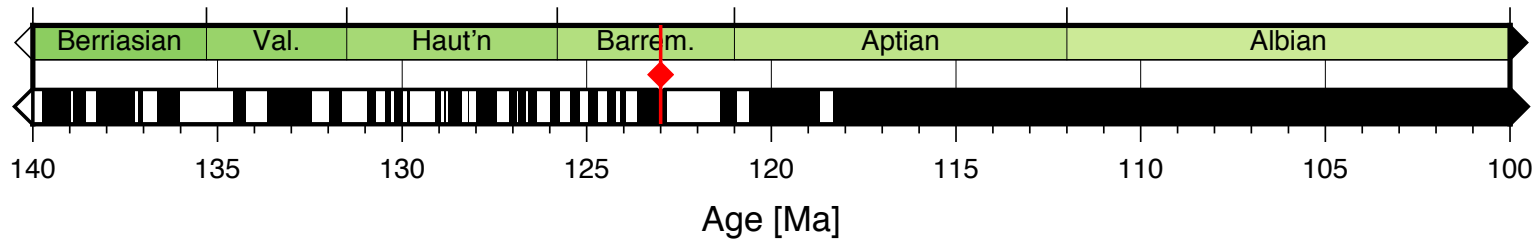




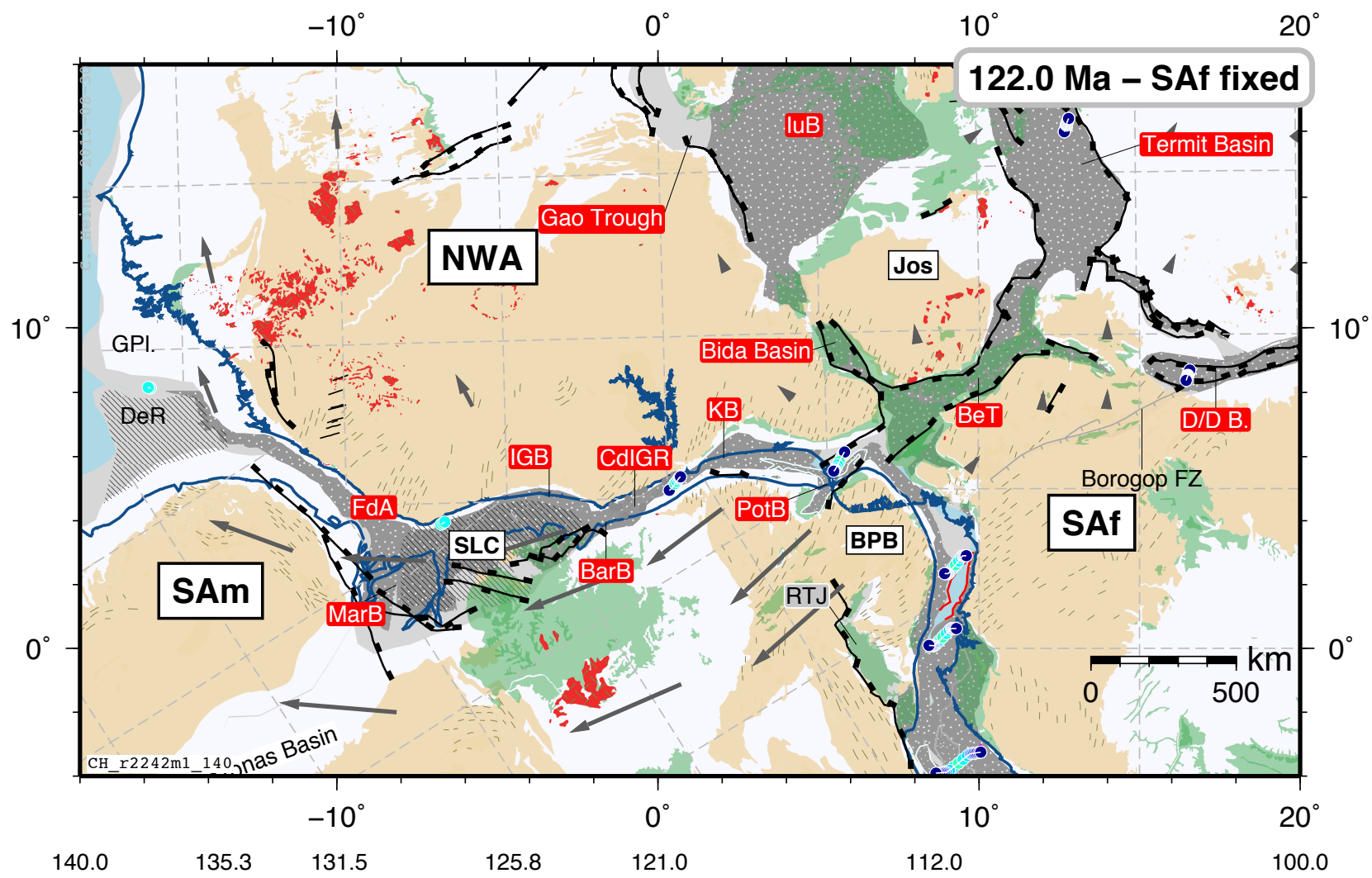

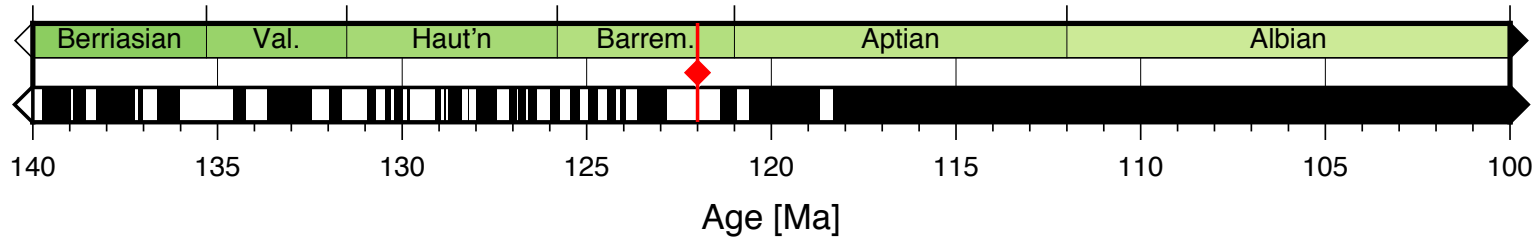




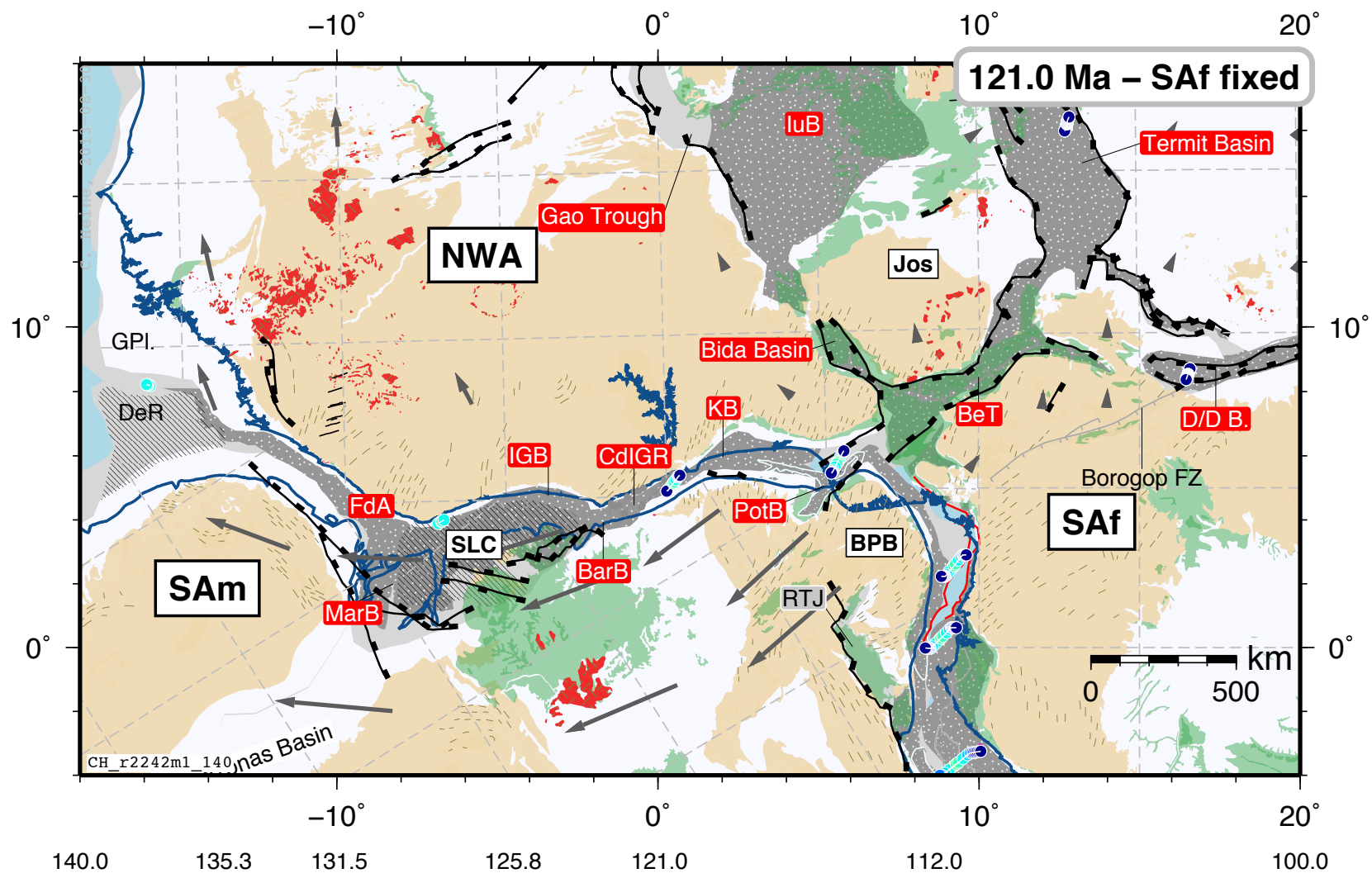

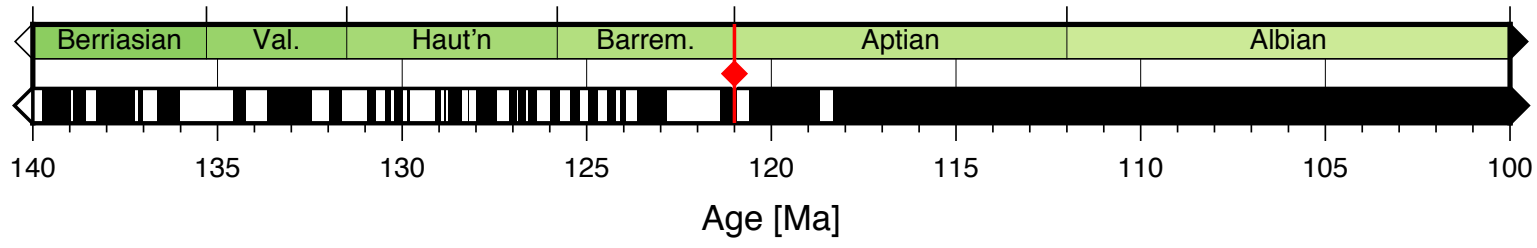



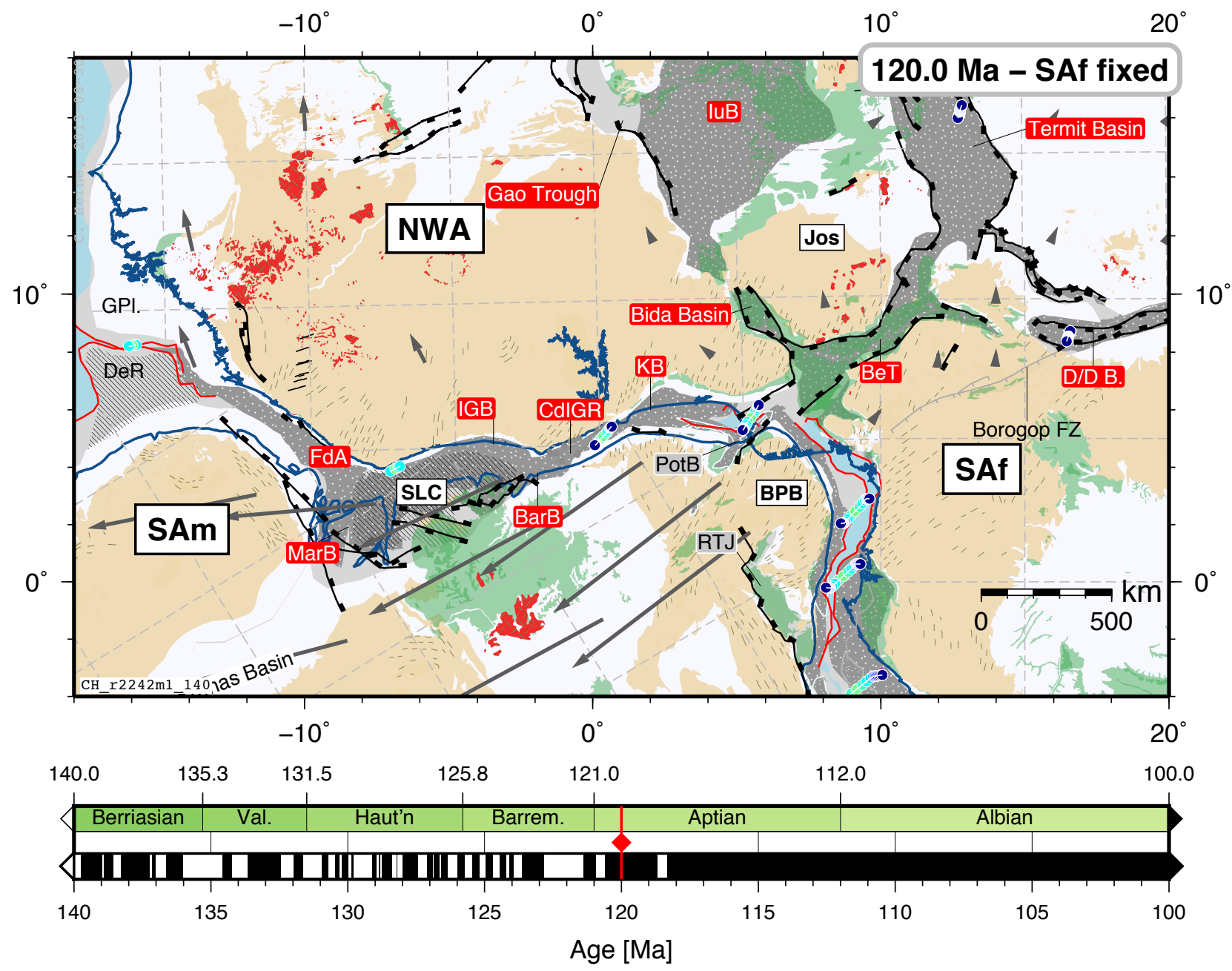


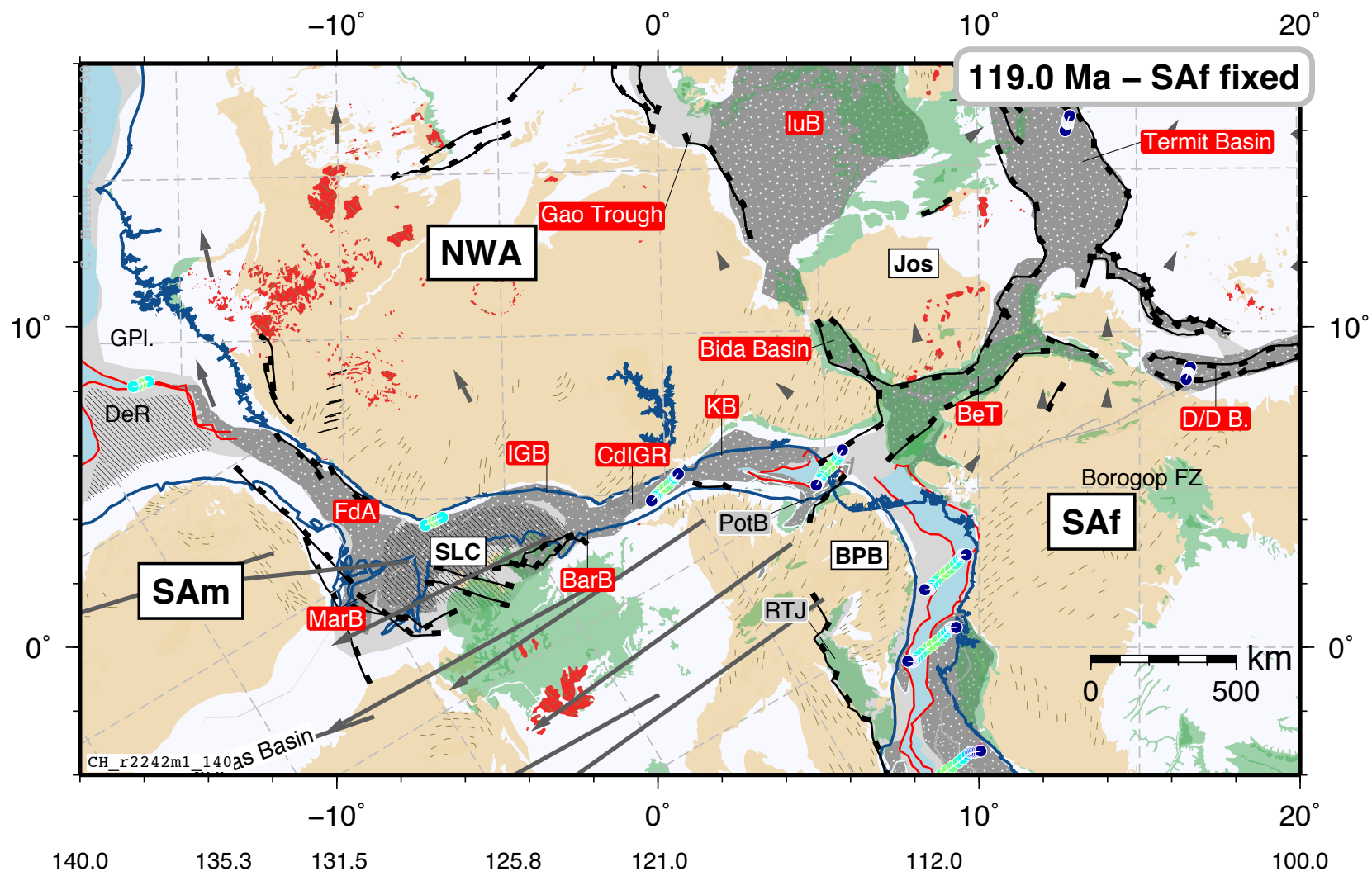

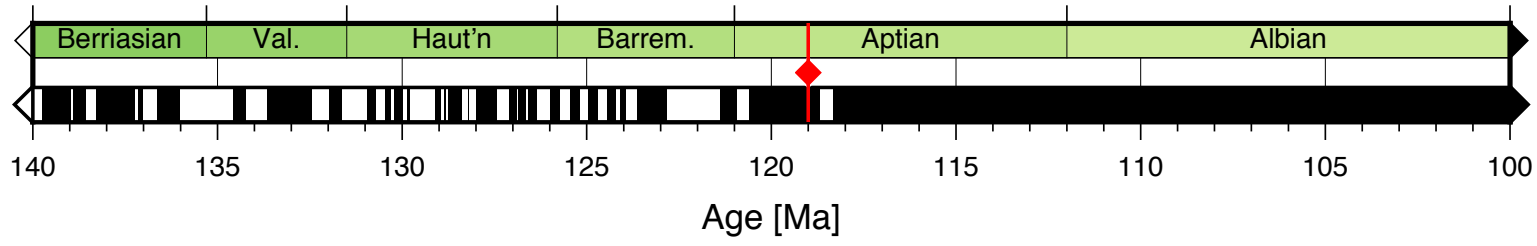




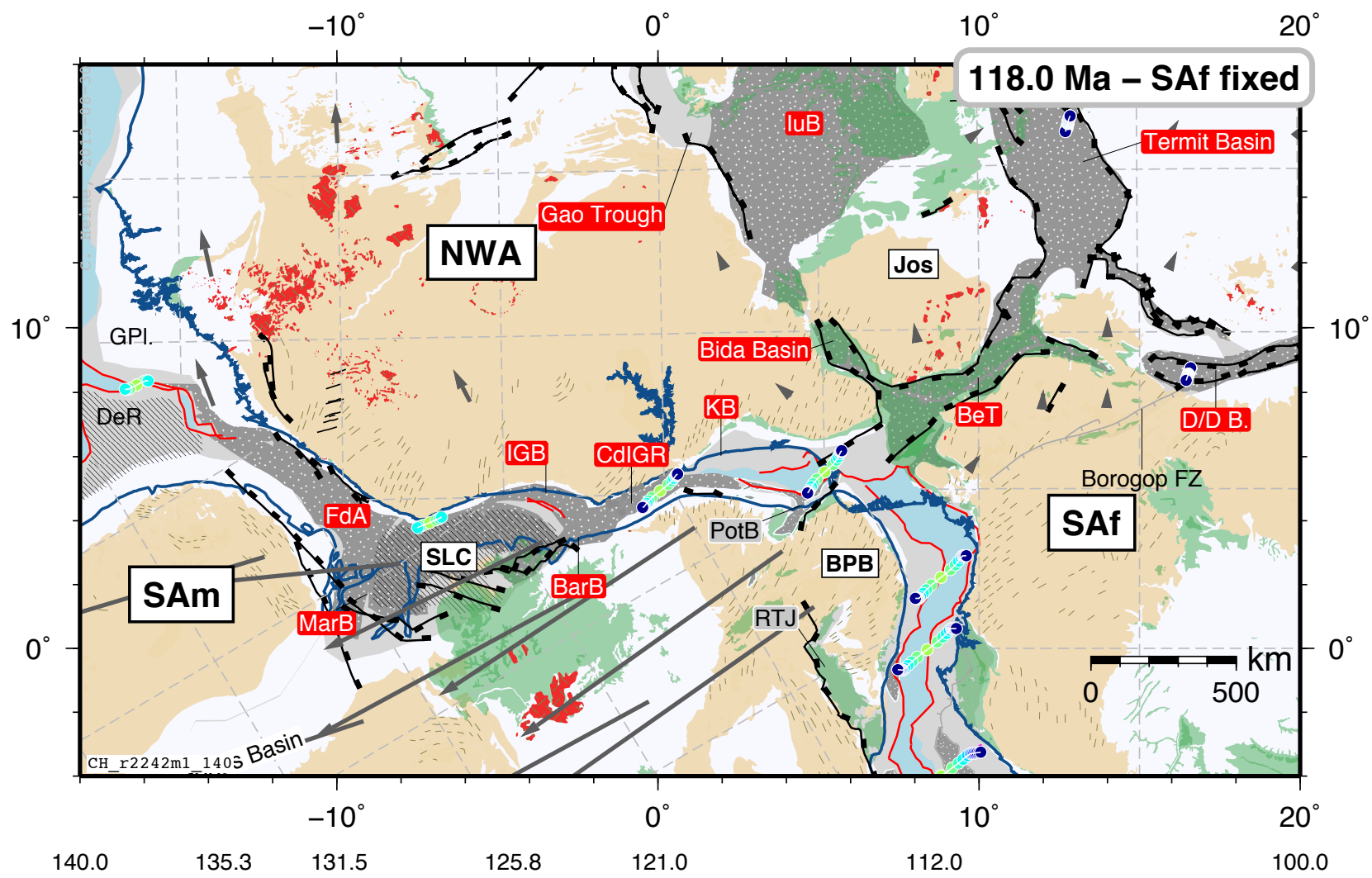

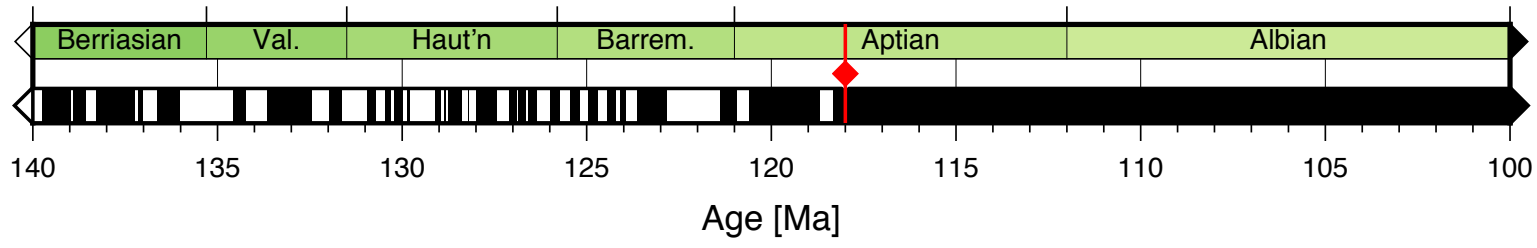



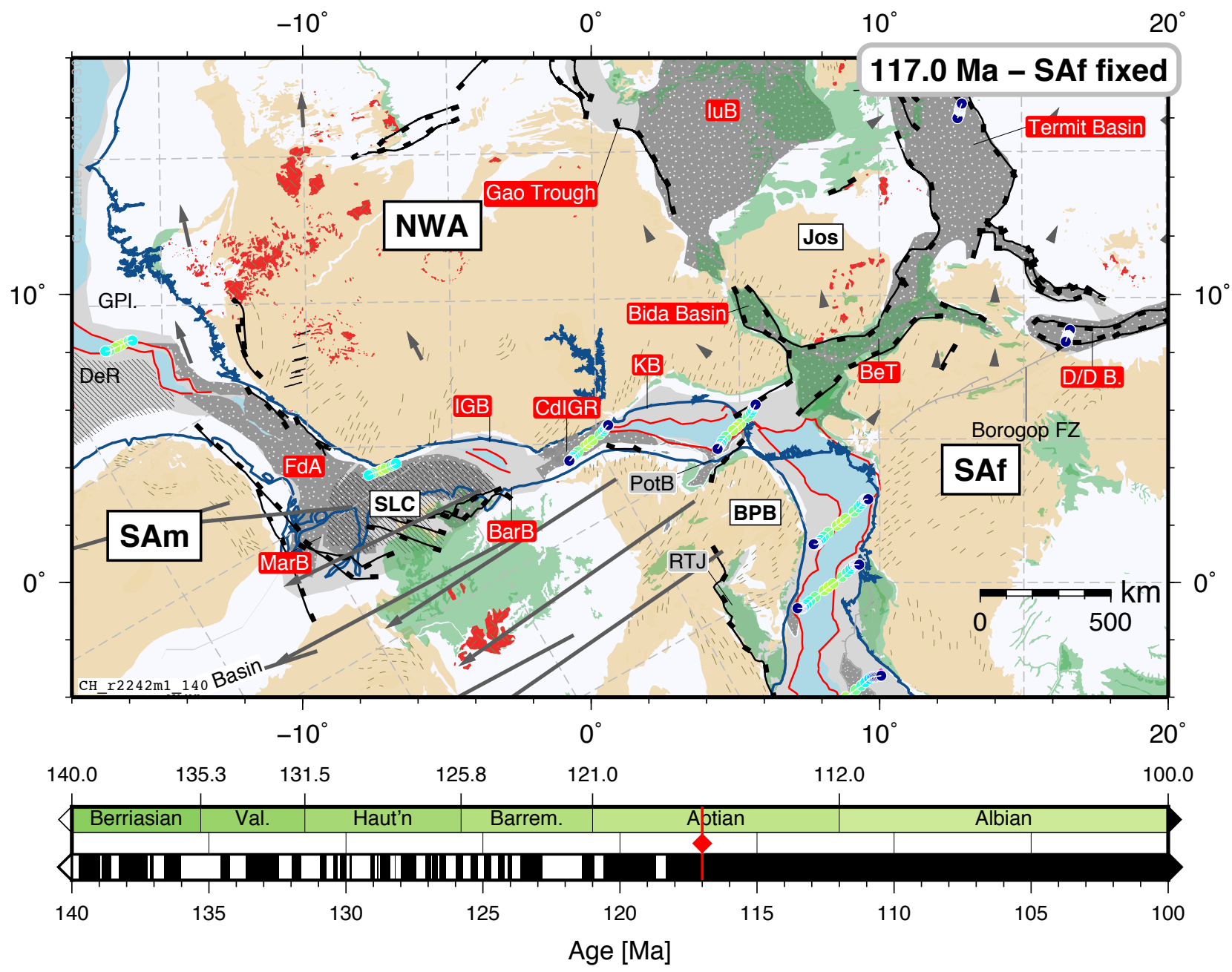


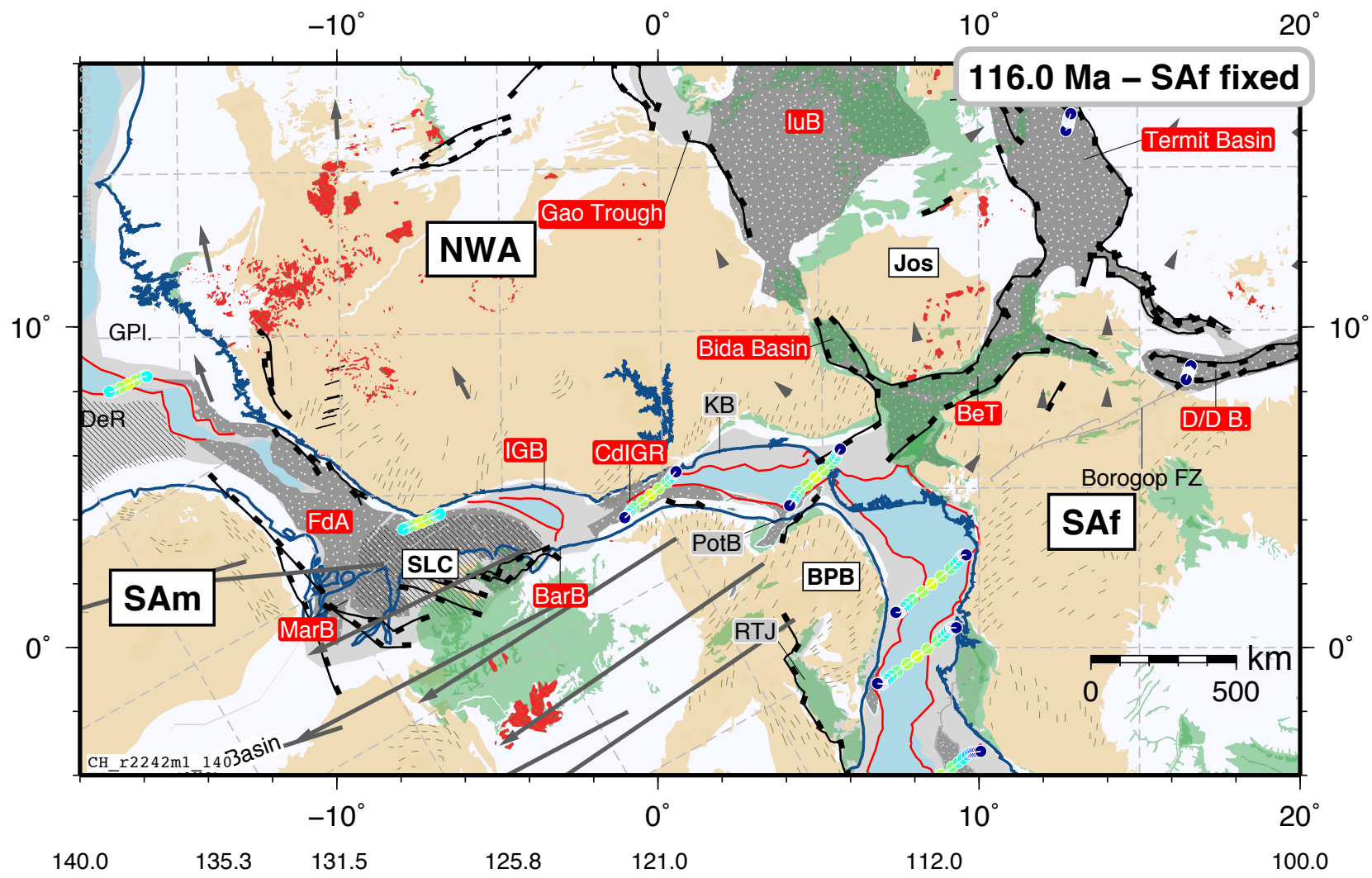

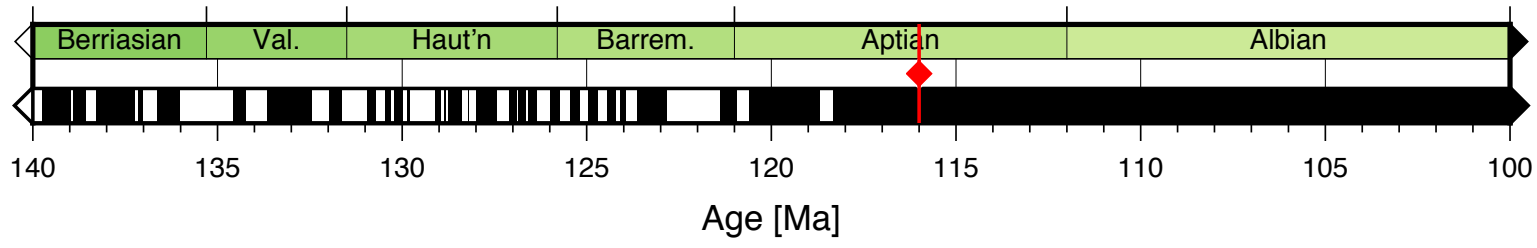




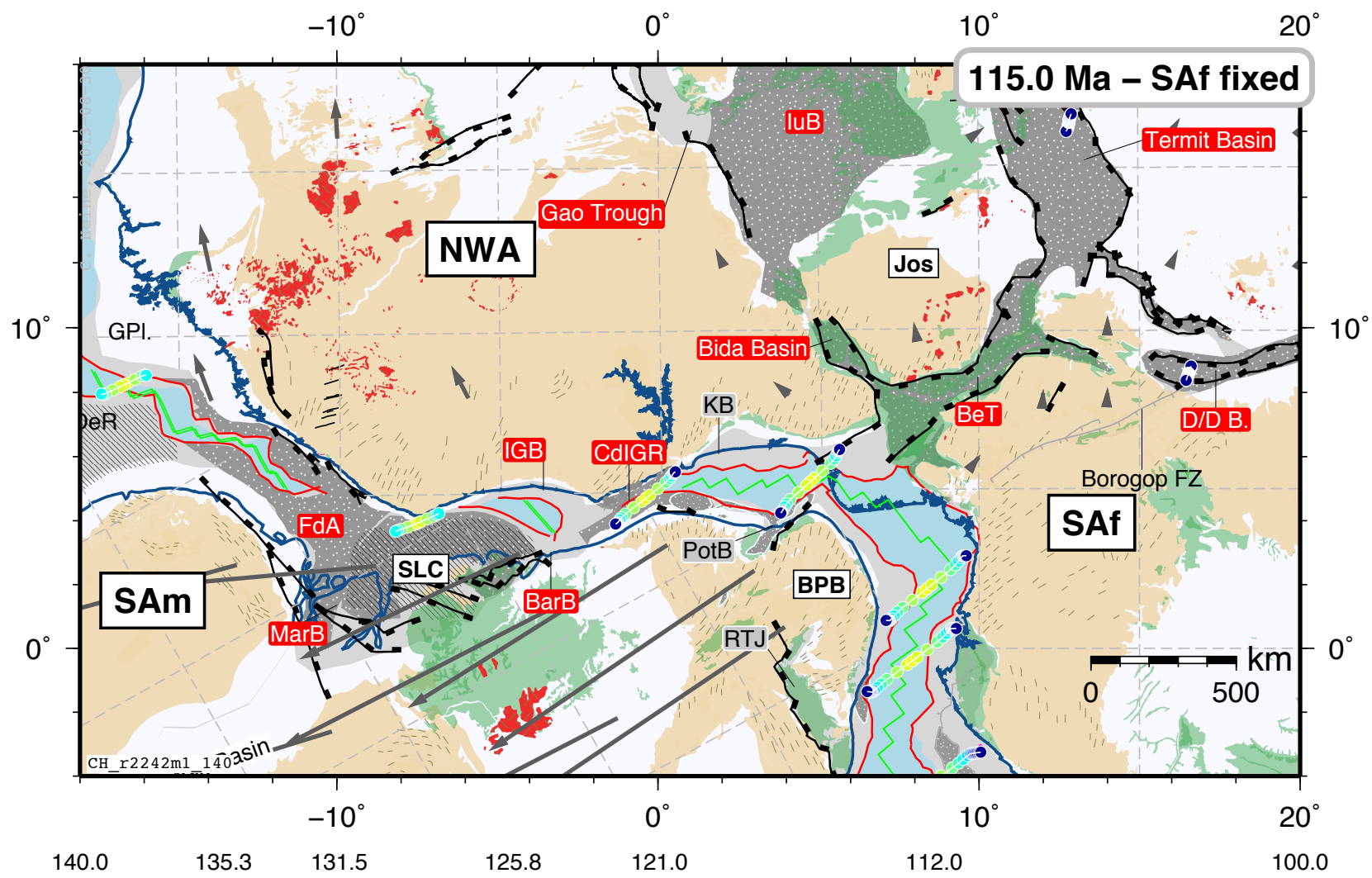

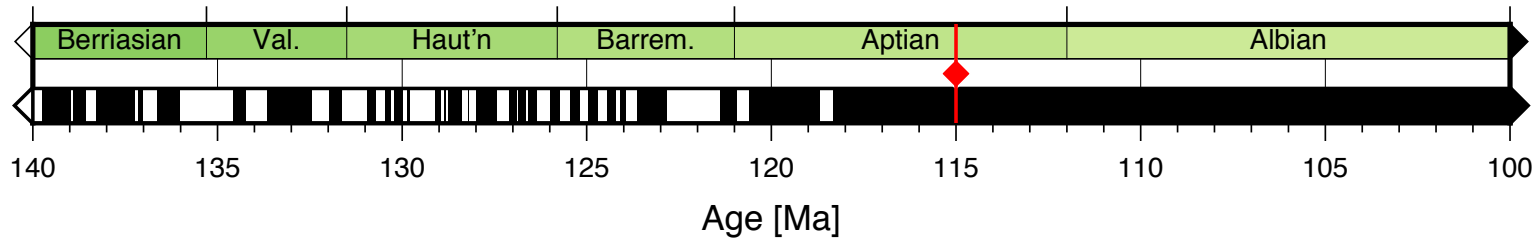



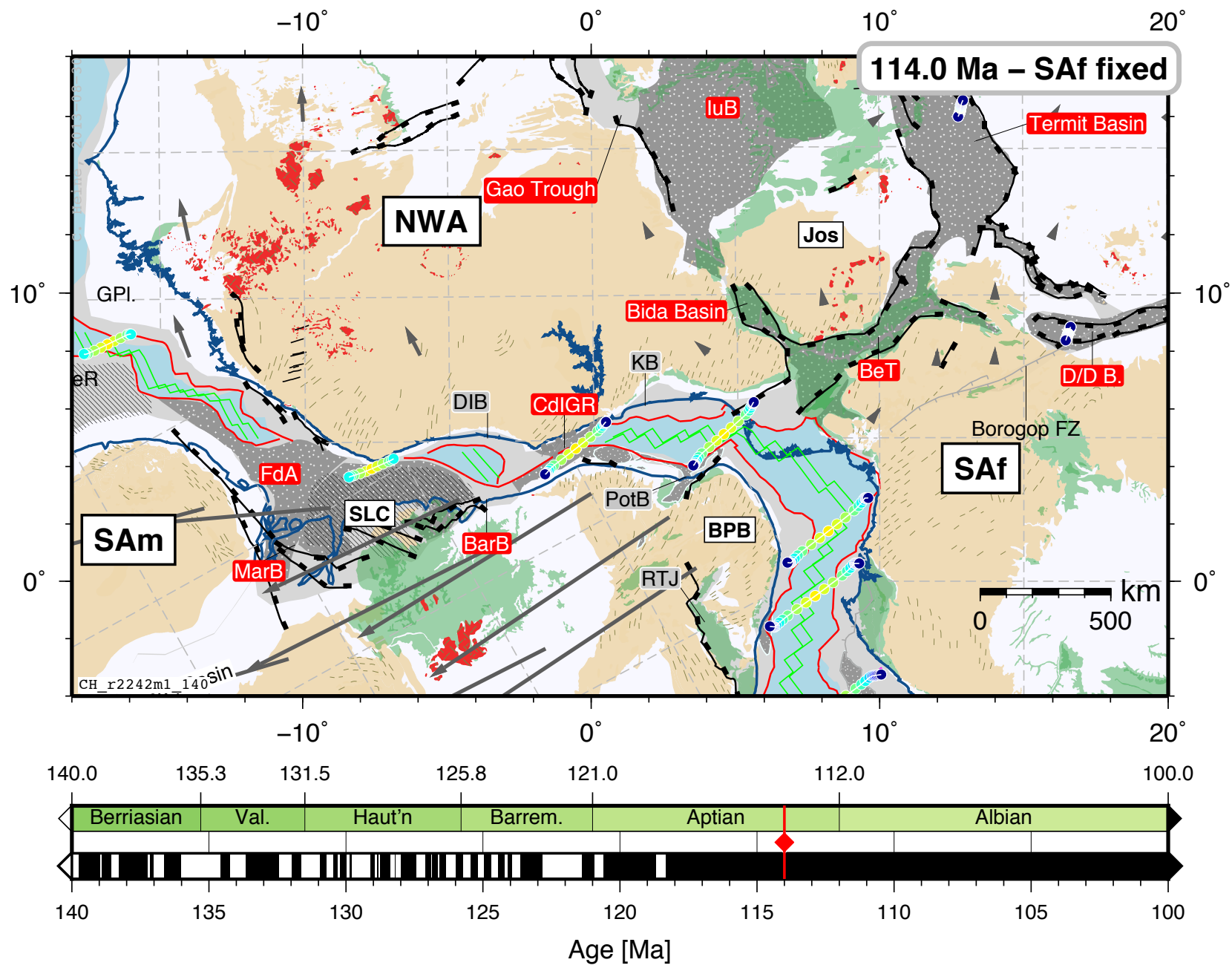

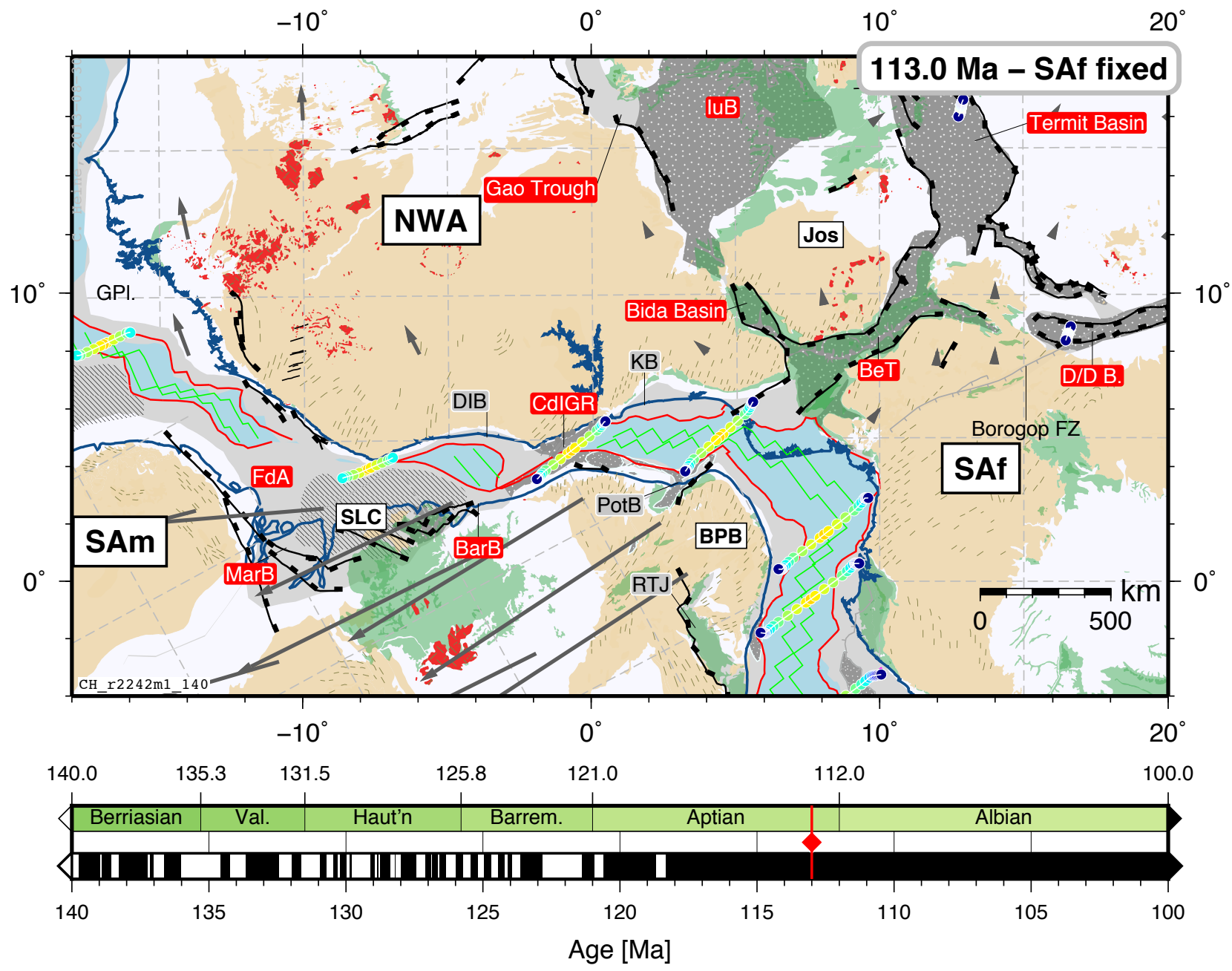

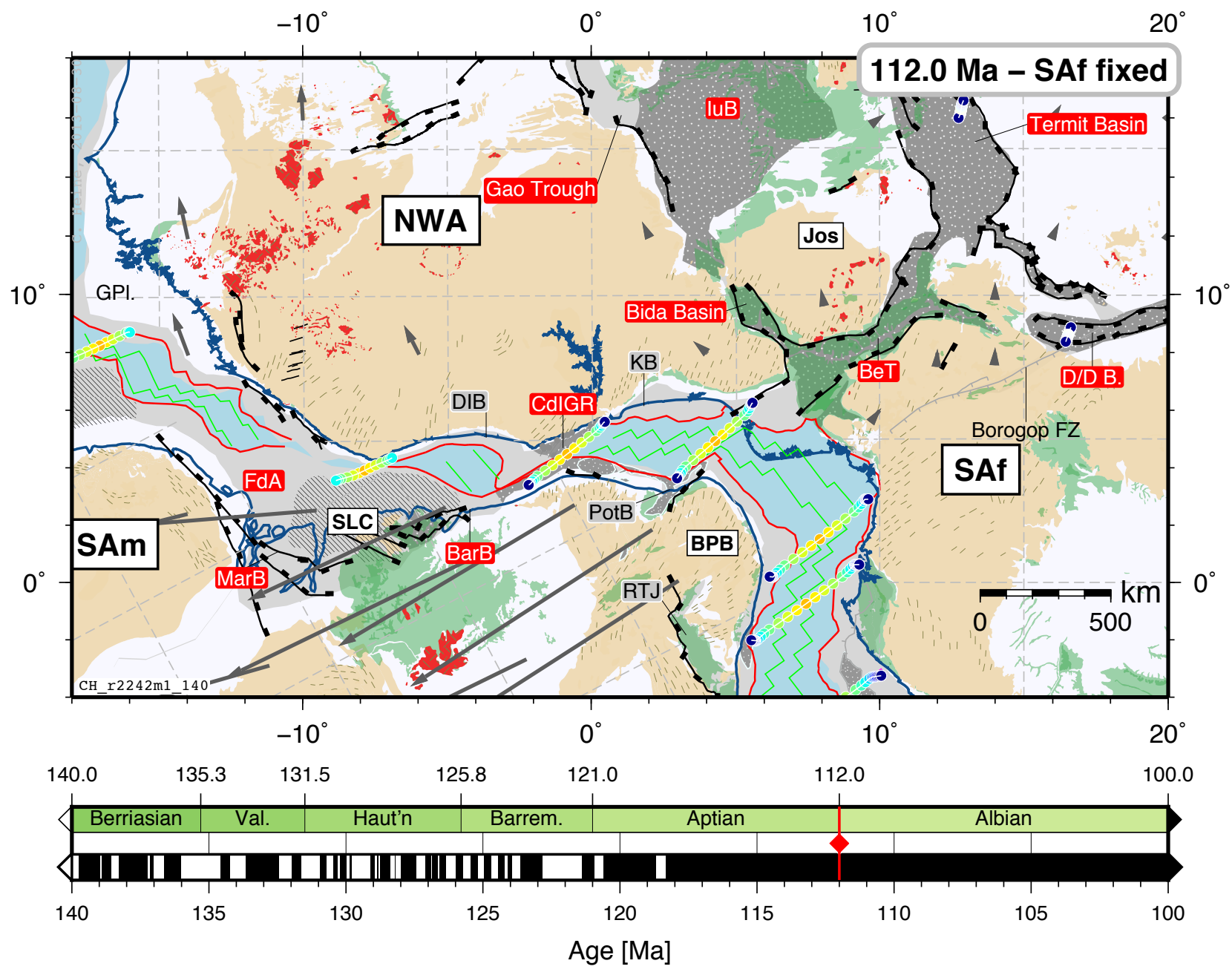

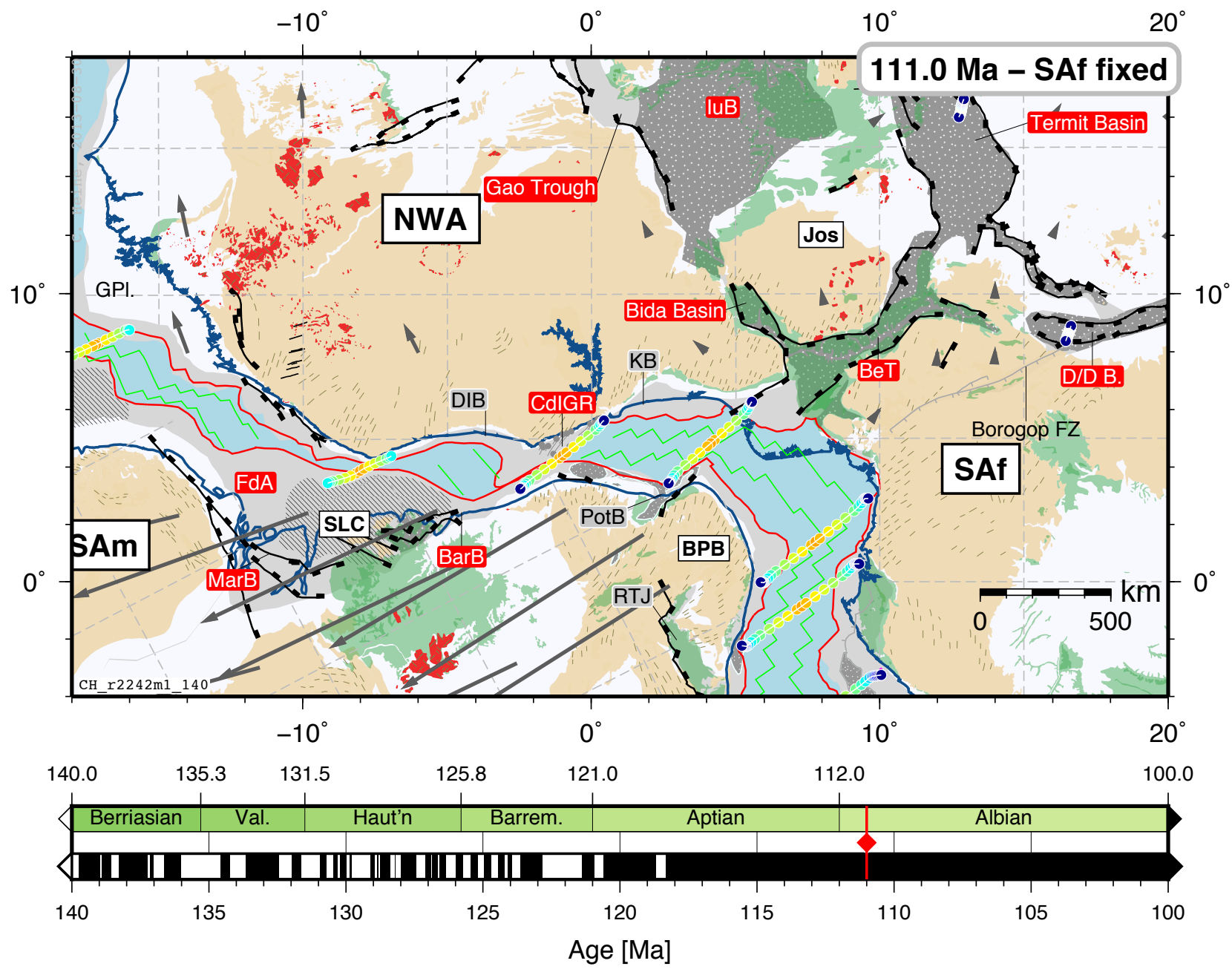

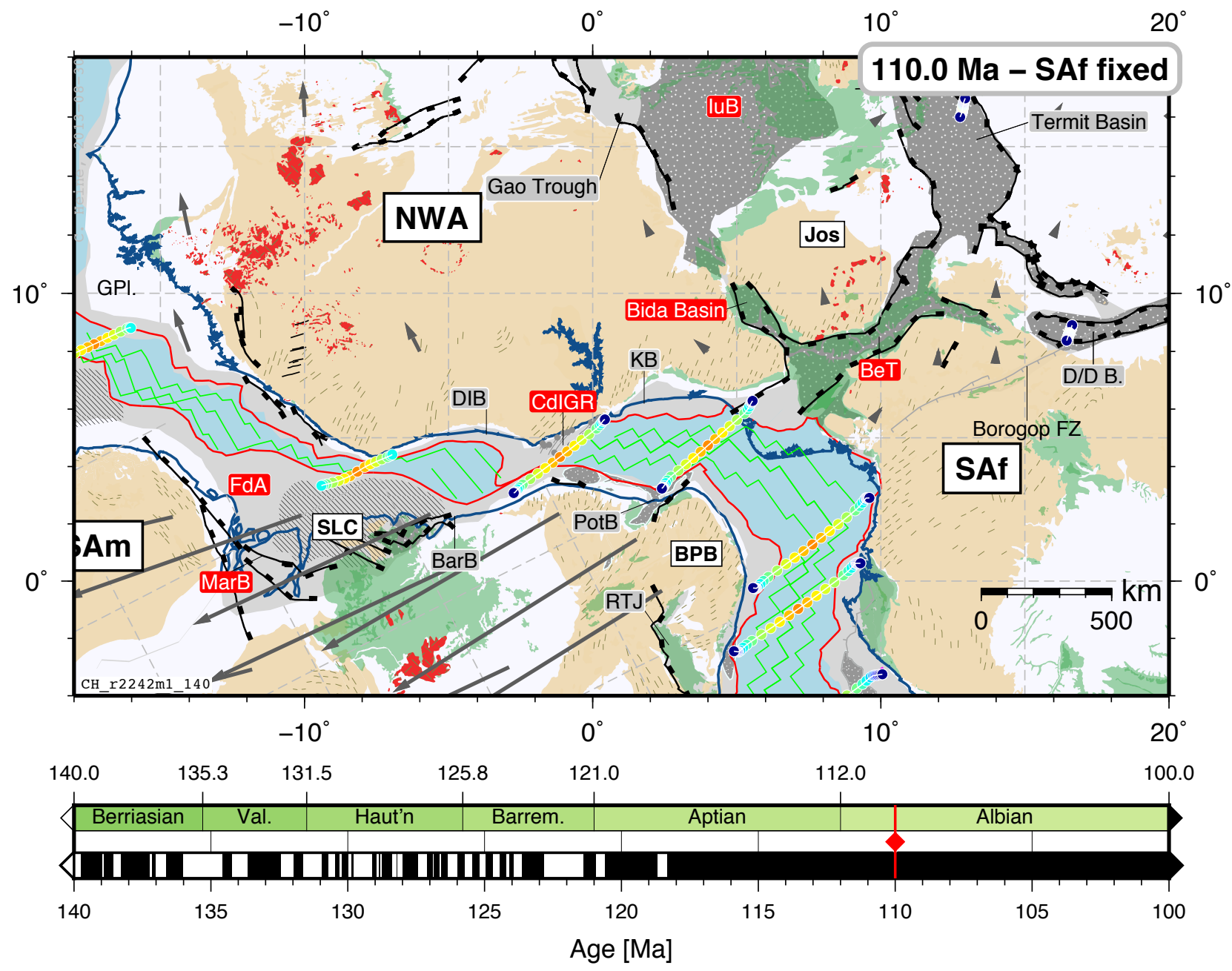


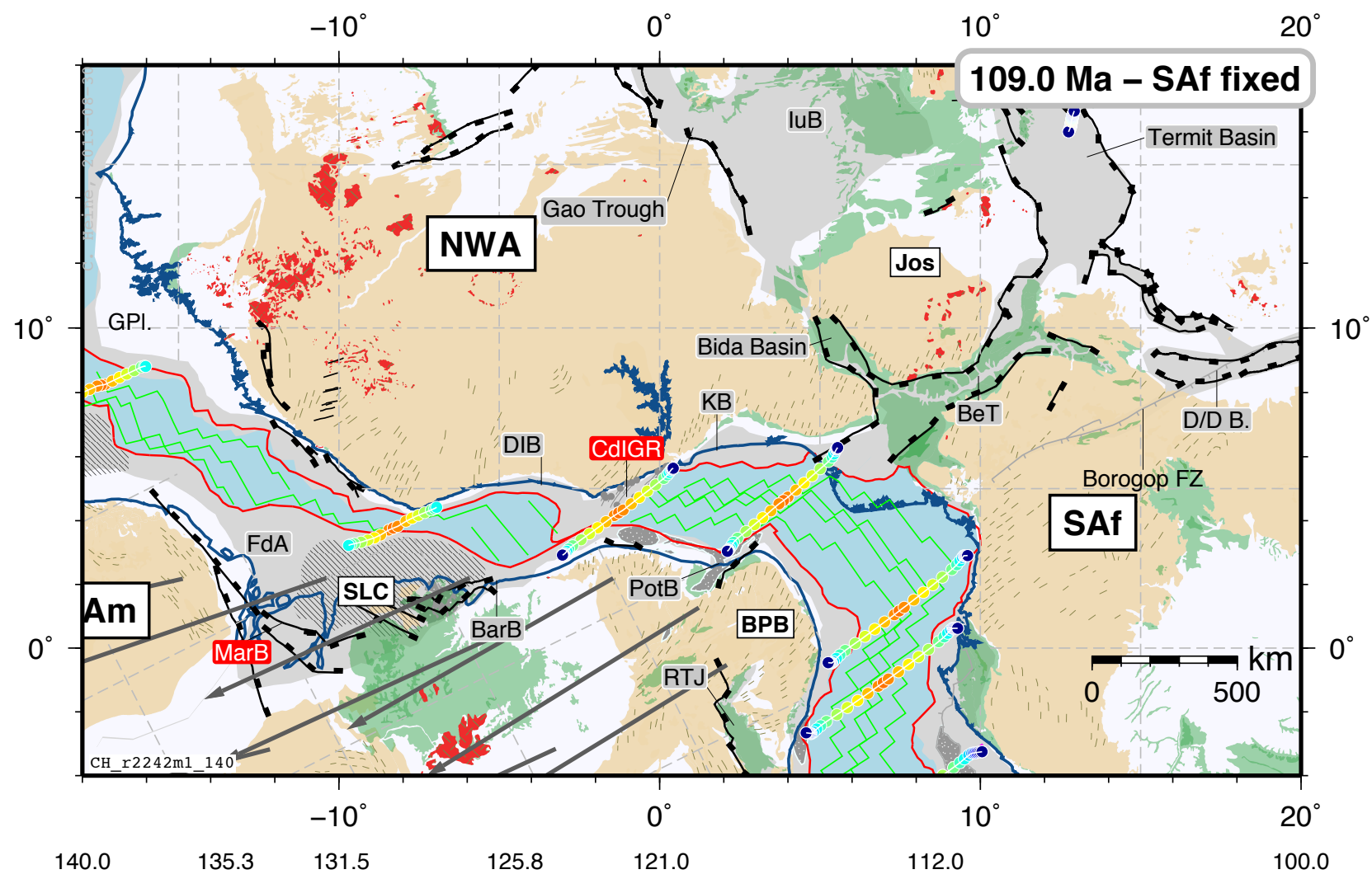

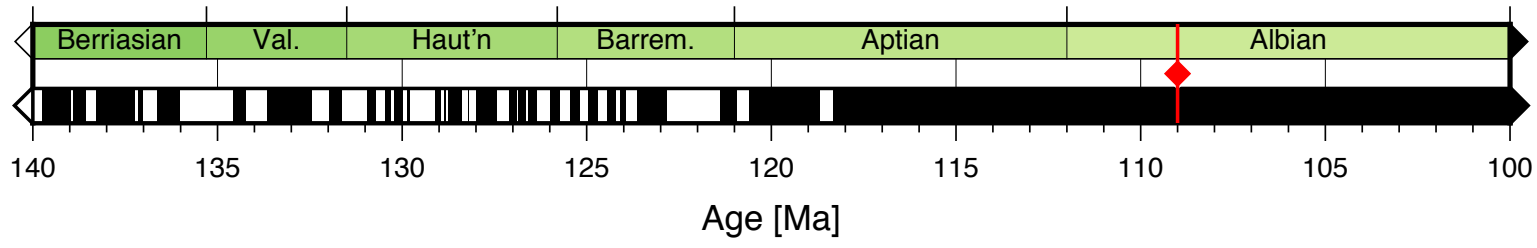




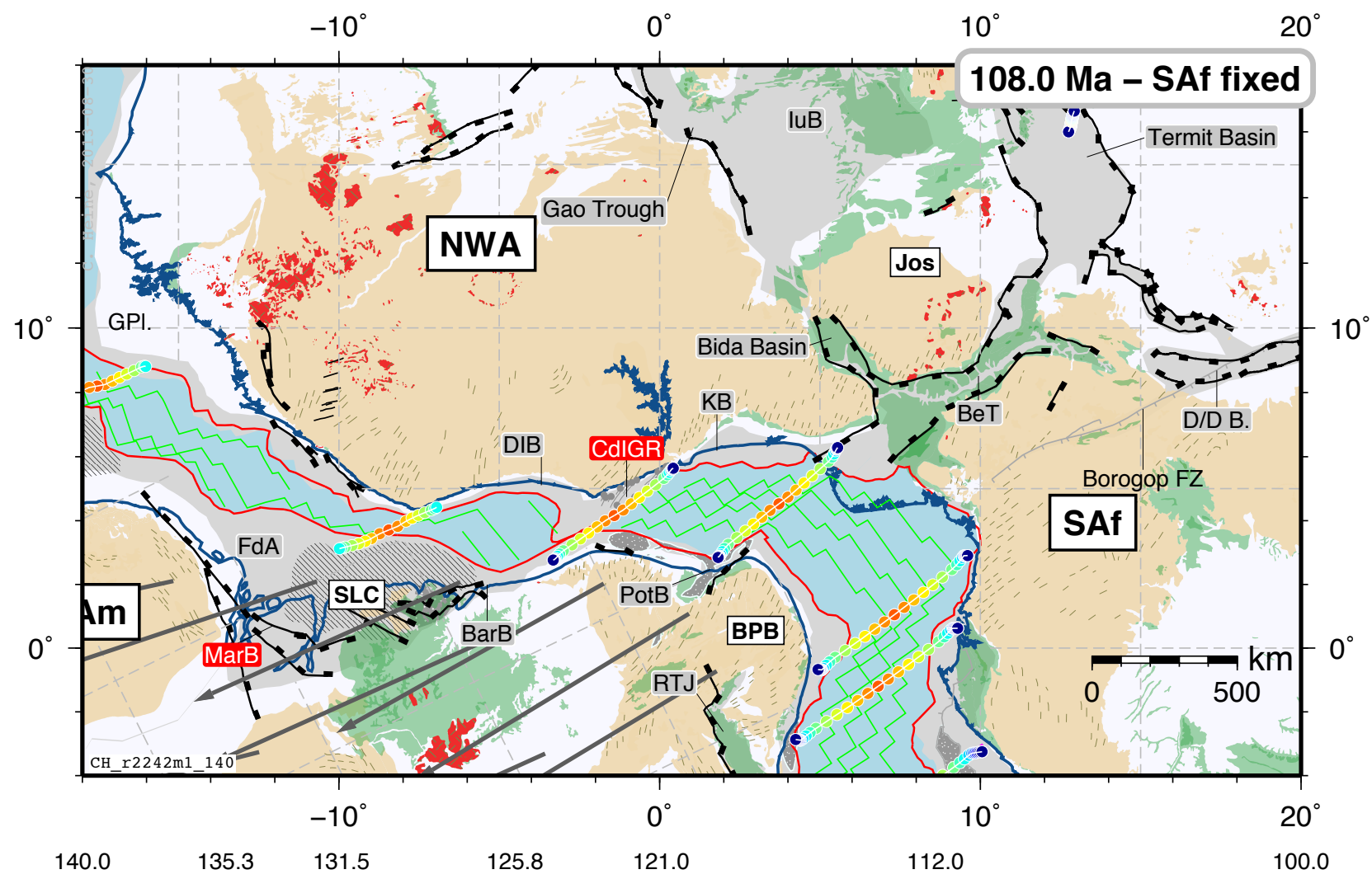

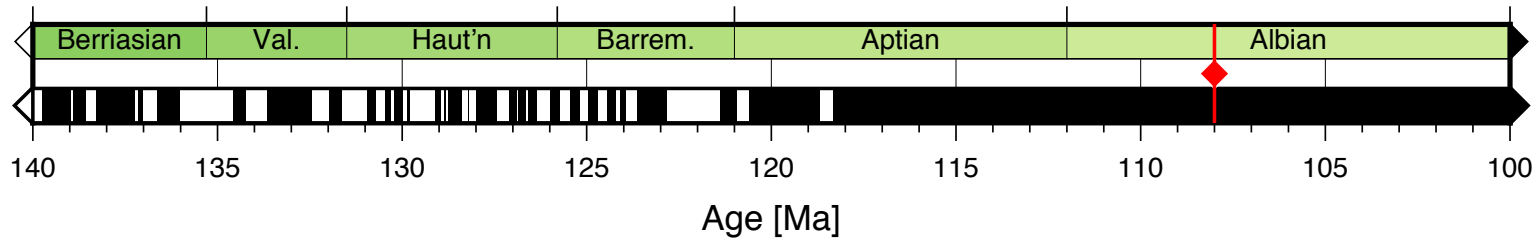




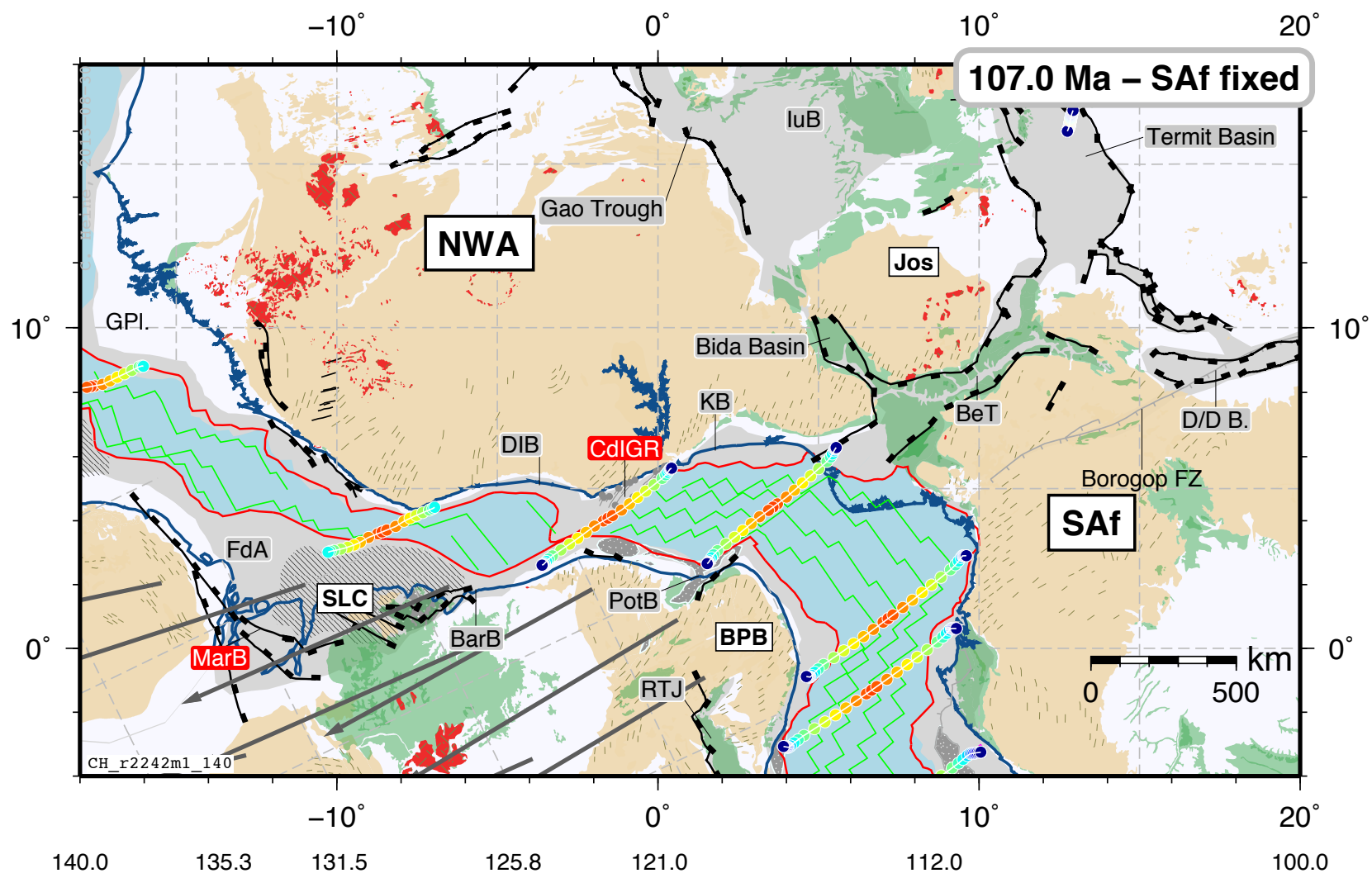

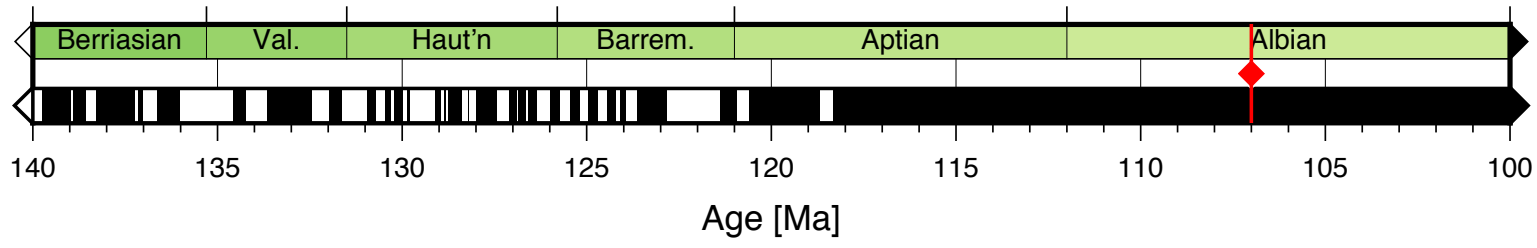




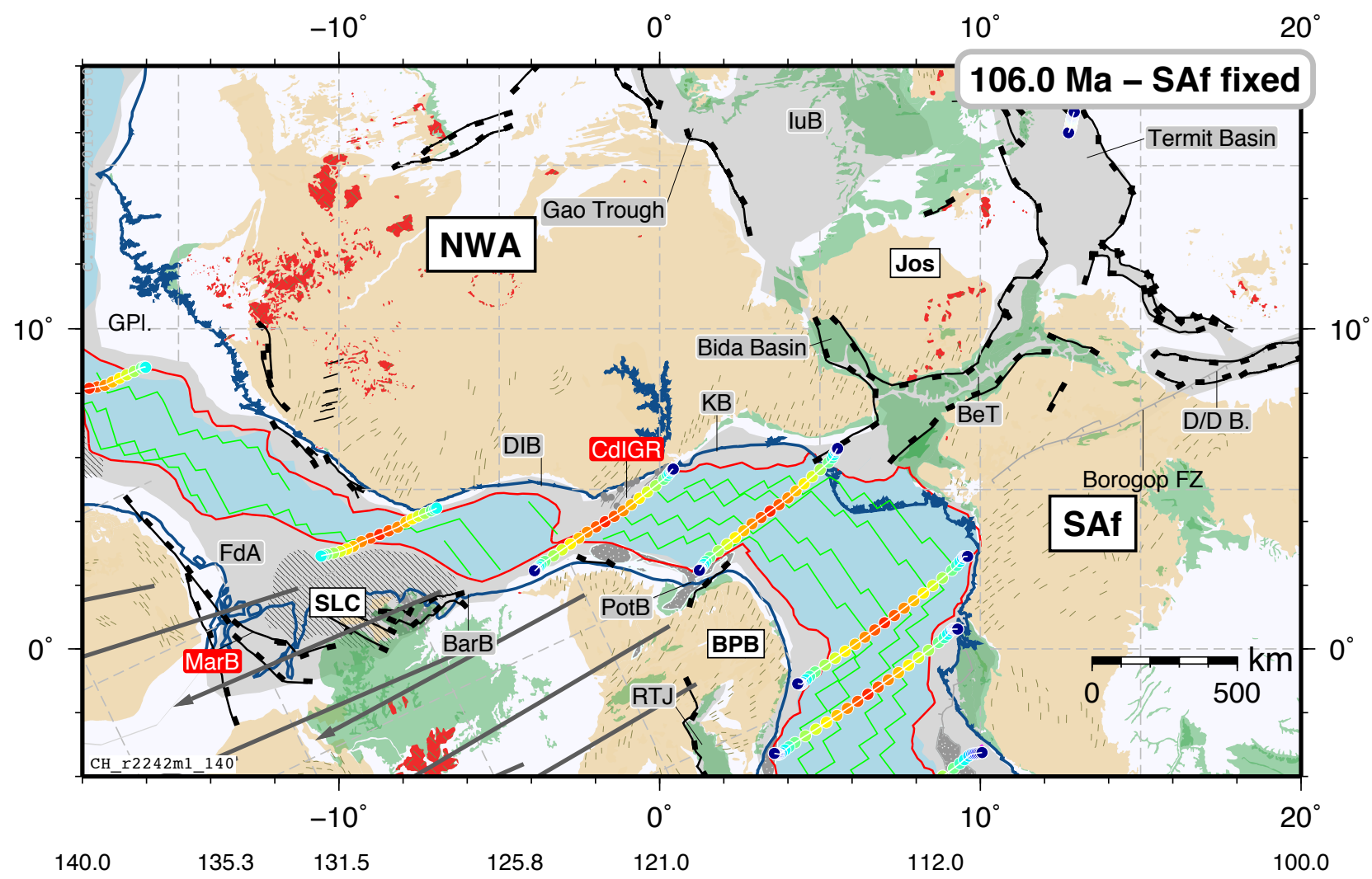

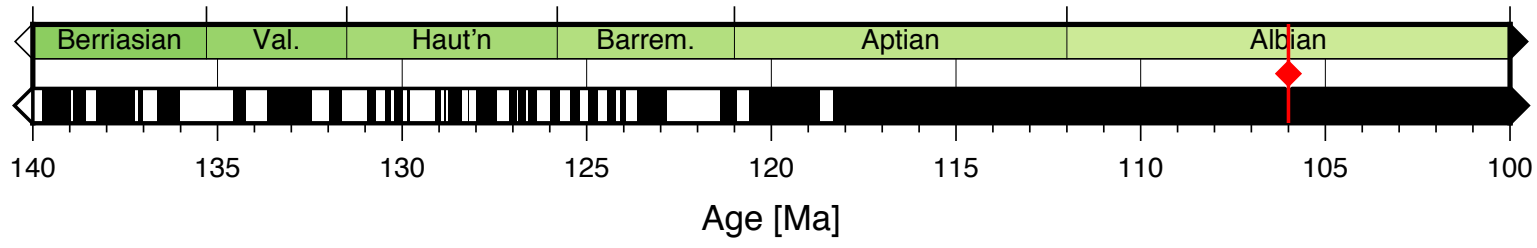




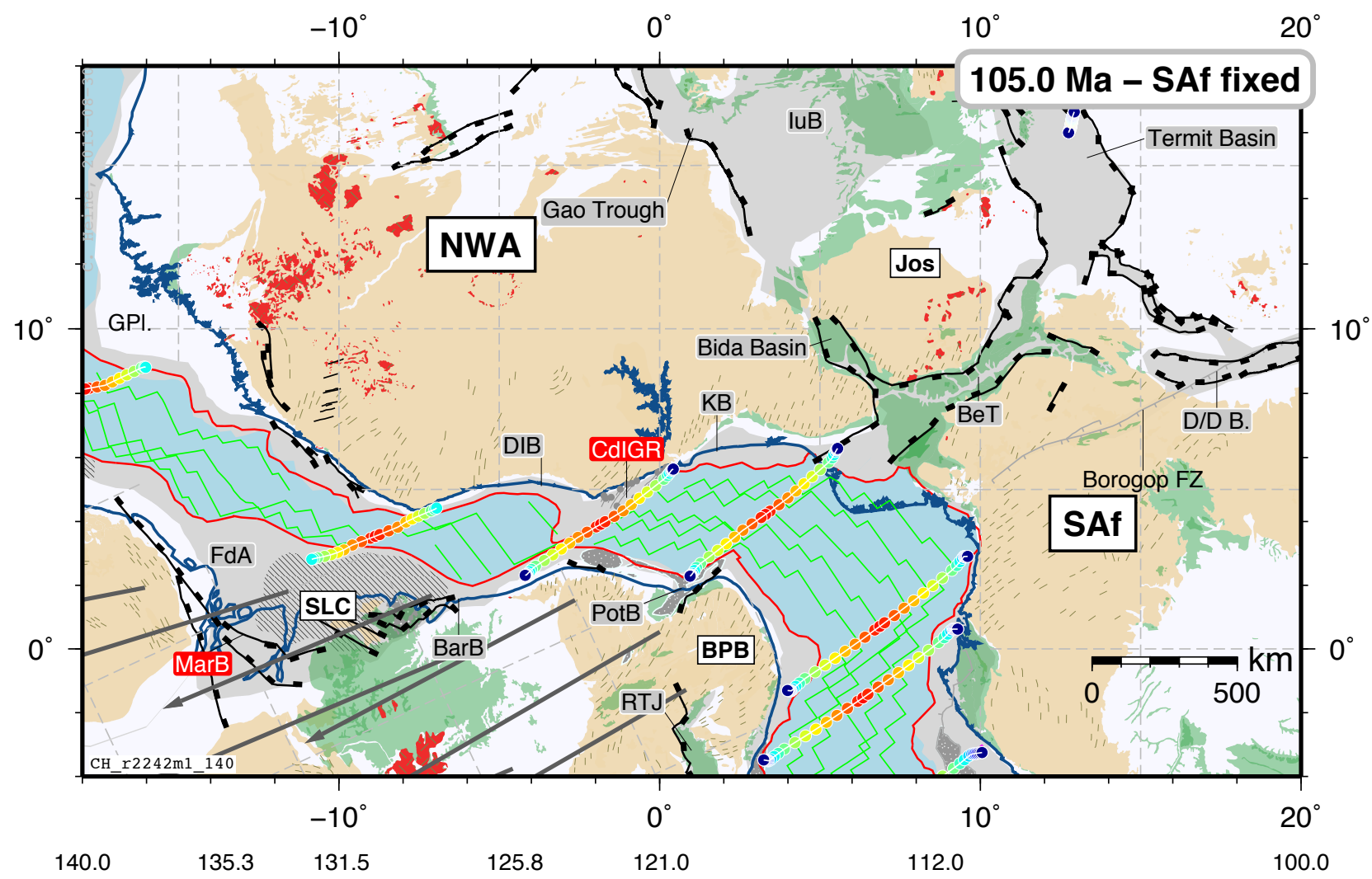

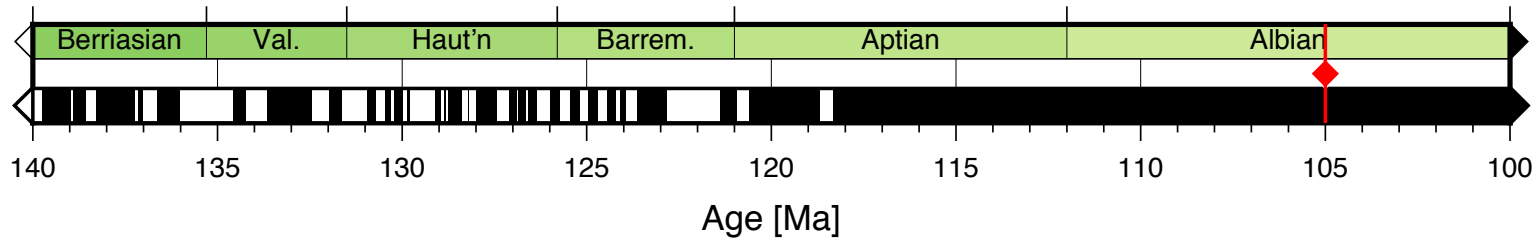




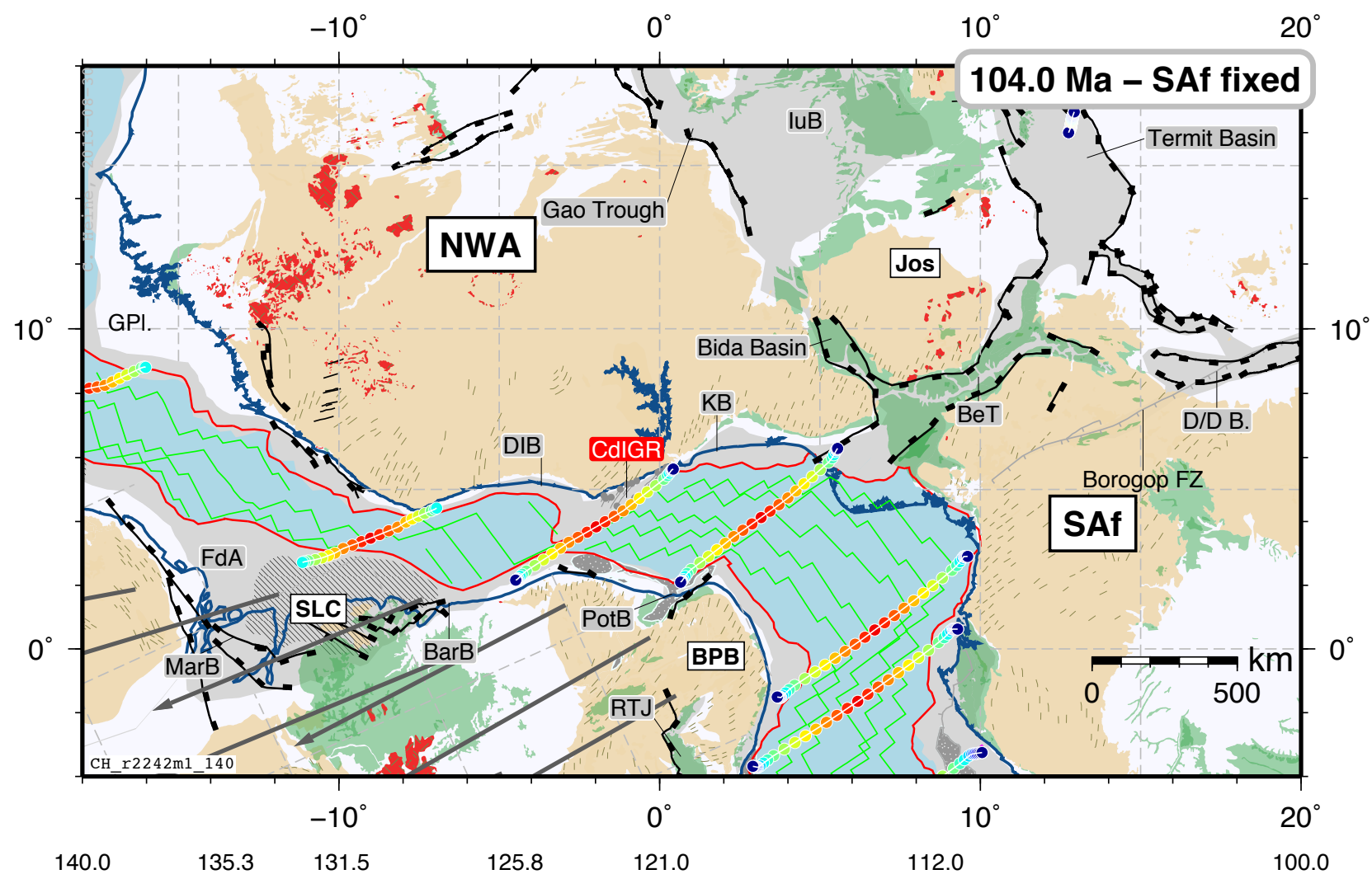

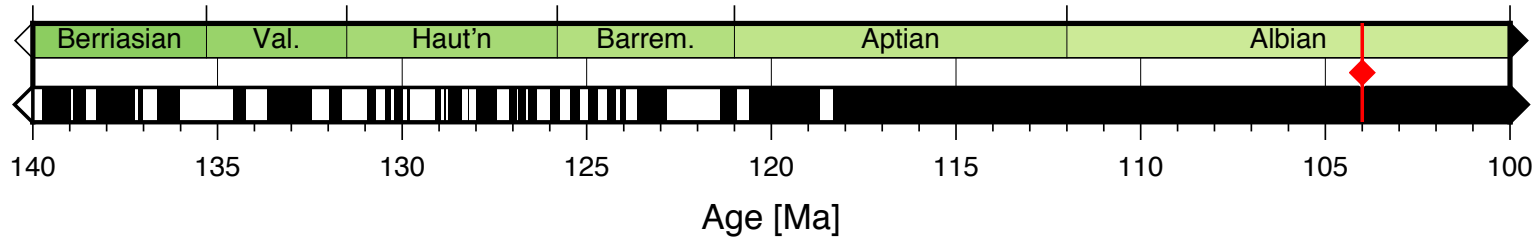




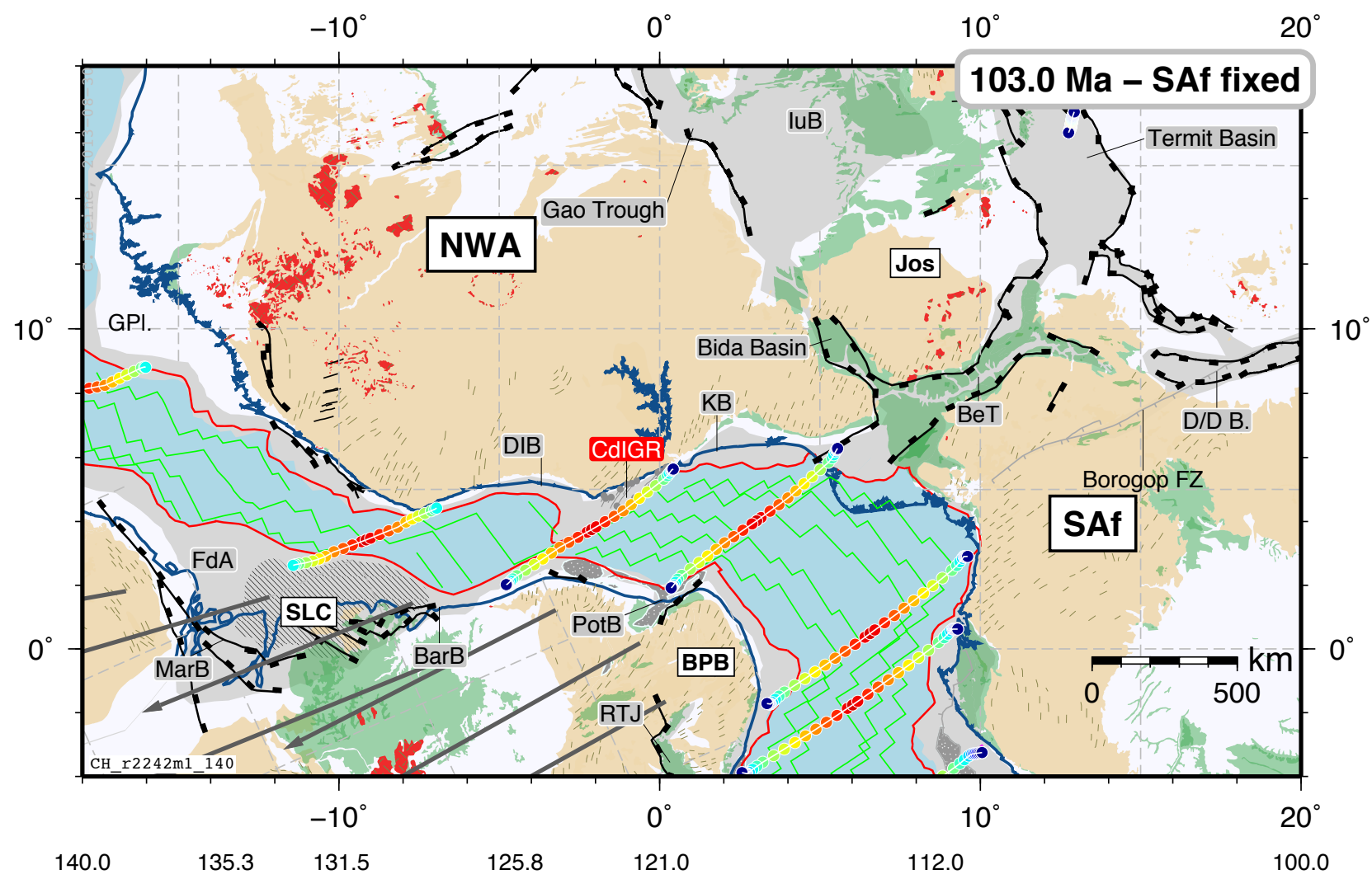

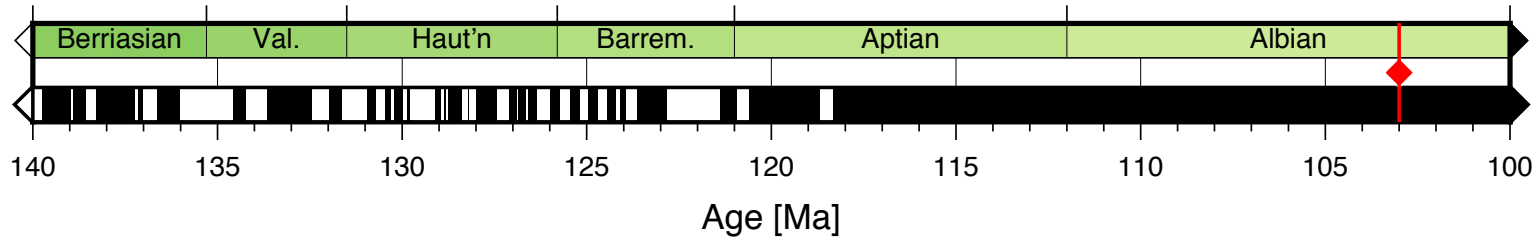




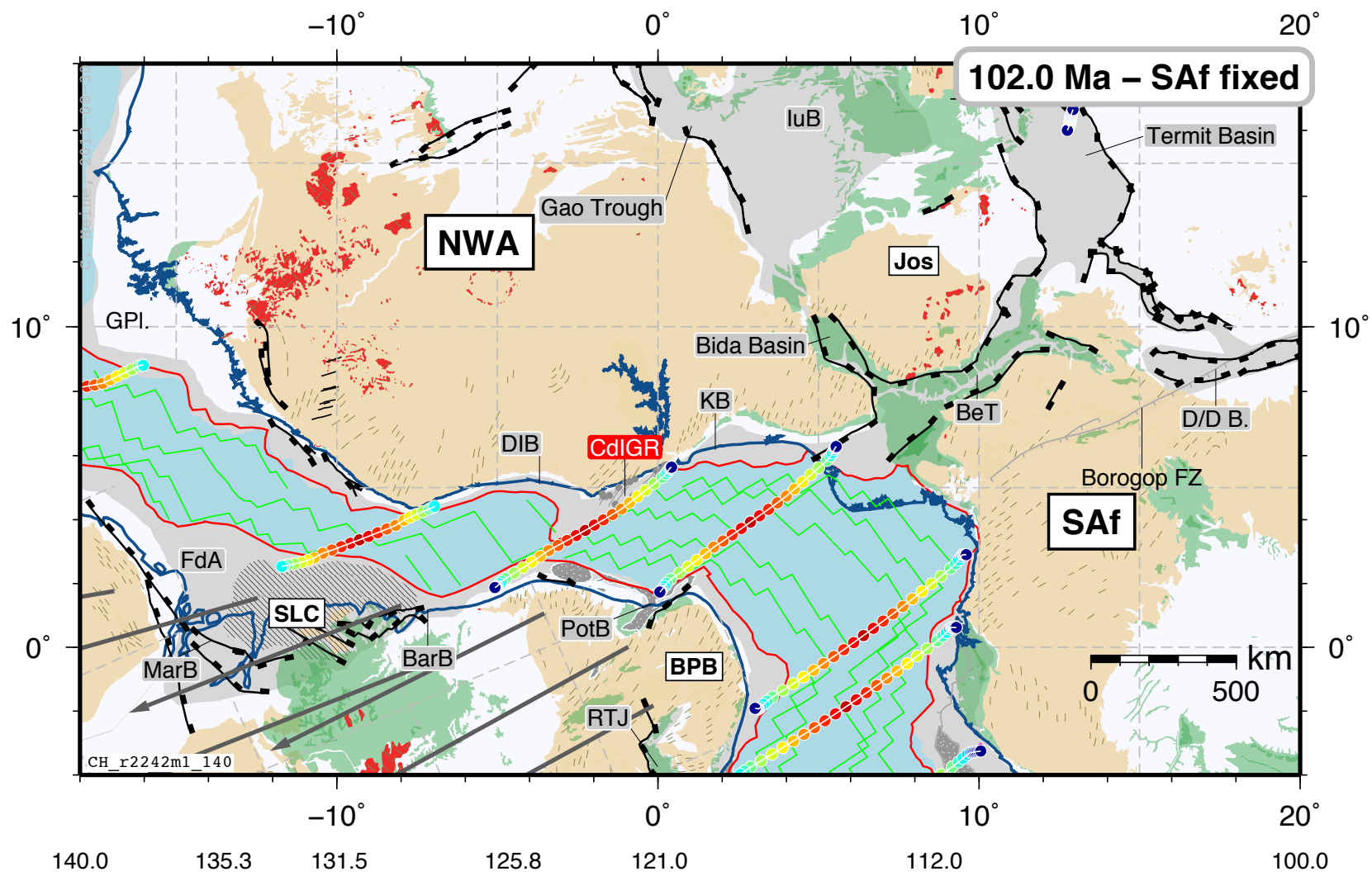

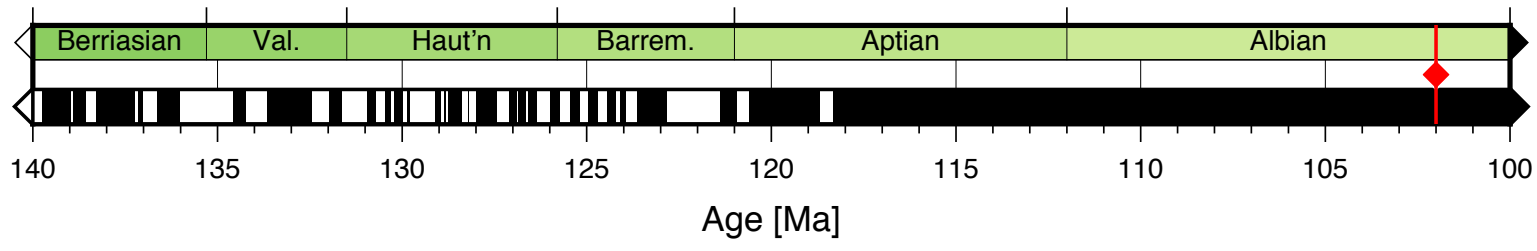




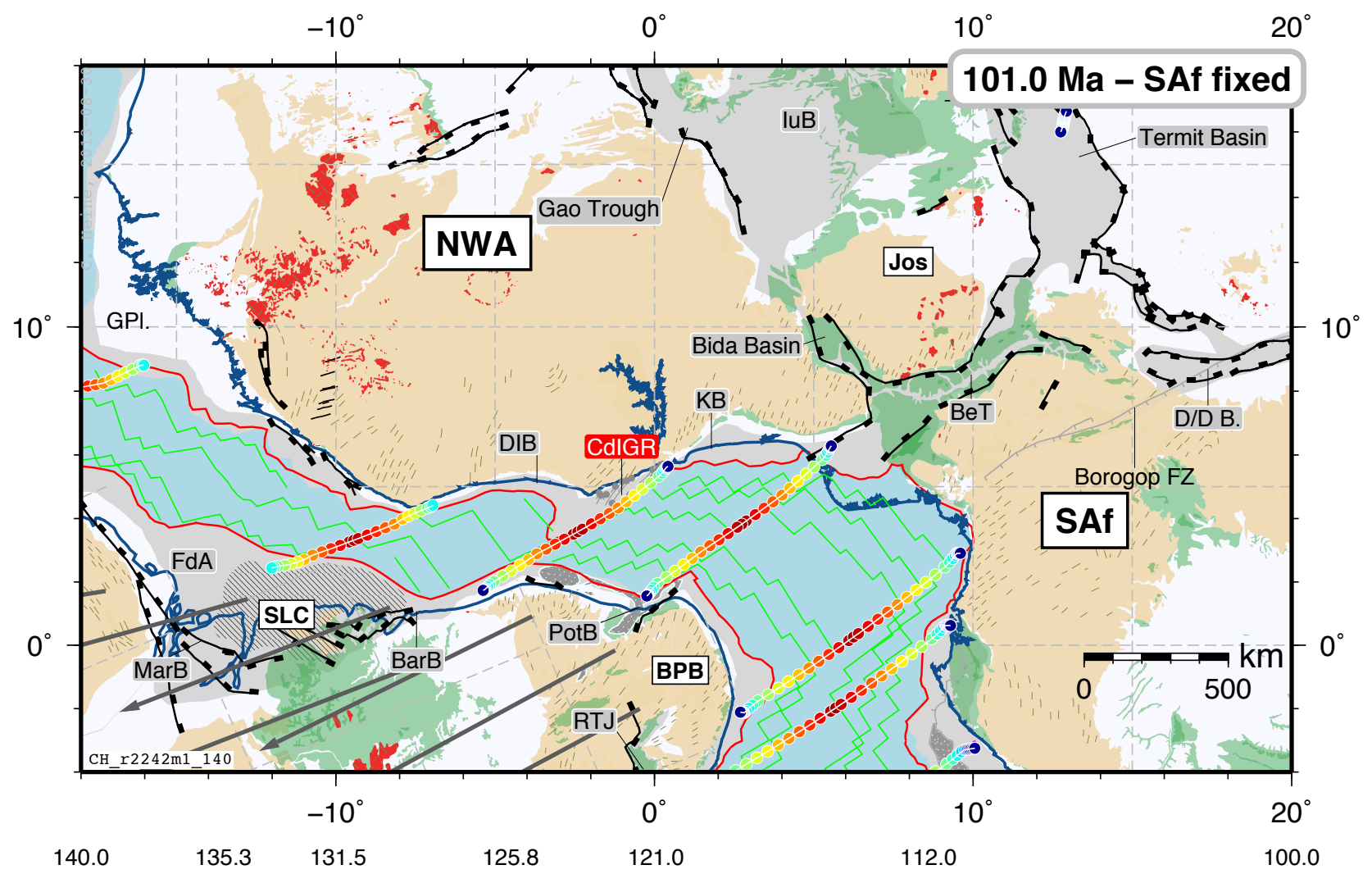

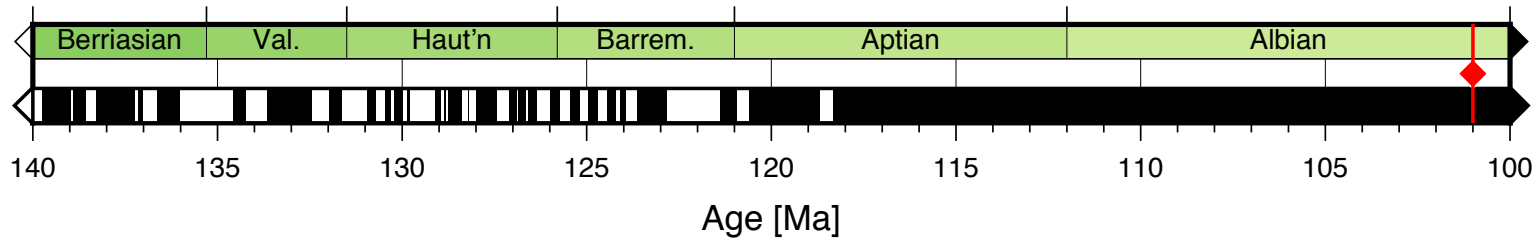




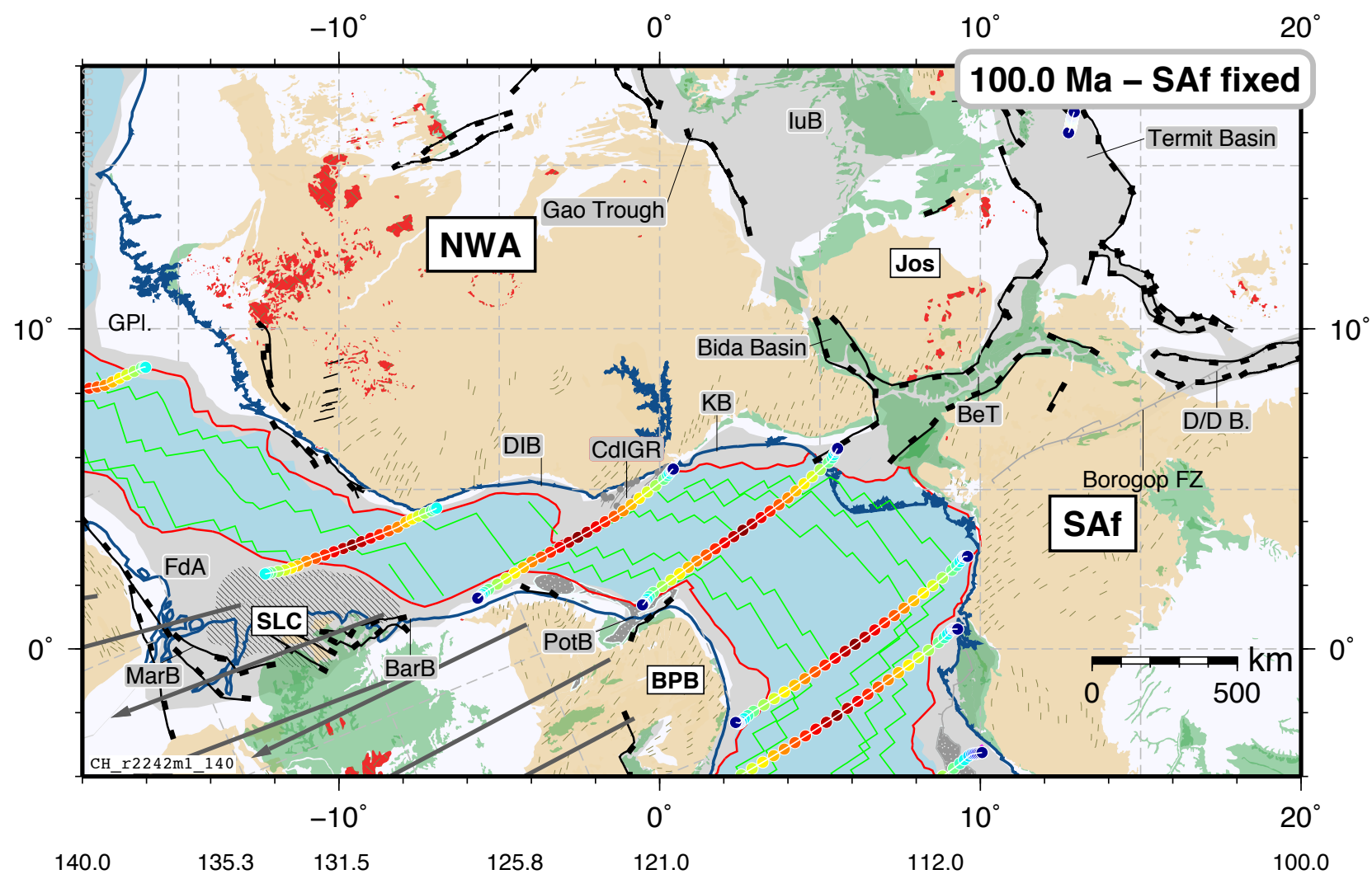

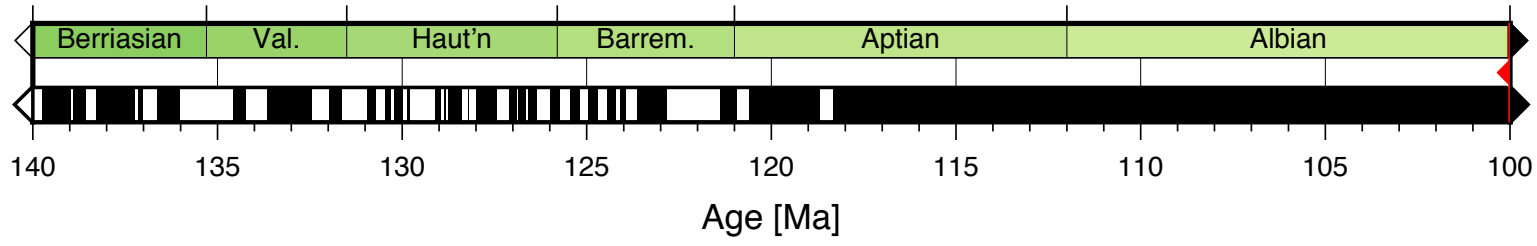




\section{-- Map legend --}

Transitional crust

Present-day continental crust

Actively deforming continental crust

Non-deforming crust

Proterozic rocks (USGS, 2012)

Strong upper crustal blocks in extensional domain

Sedimentary rocks (Jurassic-Cretaceous; USGS, CGMW)

$\square$ Igneous rocks (Mesozoic)

$\square$ Igneous rocks (Mesozoic)

Large igneous province

Pre-/Synrift Basin

Edge of Parana Flood Basalts

— Landward limit oceanic crust (LALOC)

- Restored cont. margin

- Present-day coastline

- Metam. basement grain

Magnetic isochron

_ Tectonic Lineament (regional)

_ Tectonic Lineament (regional)

- Fault (regional)

- Normal Fault (regional)

_- Thrust Fault

- Anticline

L Transfer zone dextral/sinistral (regional)

$\rightarrow$ Subduction zone

— Dyke swarm (major)

$\diamond$ Magnetic anomaly pick

5-Degree graticule

Hotspot (fixed, with $200 \mathrm{~km}$ diameter marked)

$\longrightarrow$ Velocity vector, here: $2 \mathrm{~cm} / \mathrm{a}$

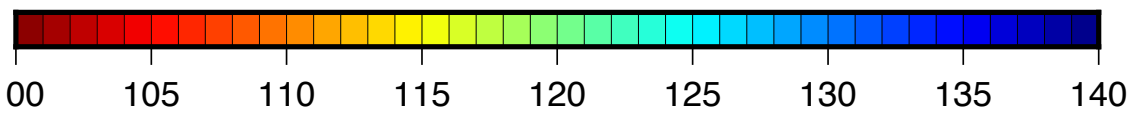

